San Jose State University

SJSU ScholarWorks

Master's Theses

Master's Theses and Graduate Research

Fall 2015

\title{
Geographic Variation in the Life History and Morphology of the Pacific Geoduck, Panopea generosa
}

Gabriela Navas

San Jose State University

Follow this and additional works at: https://scholarworks.sjsu.edu/etd_theses

\section{Recommended Citation}

Navas, Gabriela, "Geographic Variation in the Life History and Morphology of the Pacific Geoduck, Panopea generosa" (2015). Master's Theses. 4658.

DOI: https://doi.org/10.31979/etd.r73g-2xad

https://scholarworks.sjsu.edu/etd_theses/4658

This Thesis is brought to you for free and open access by the Master's Theses and Graduate Research at SJSU ScholarWorks. It has been accepted for inclusion in Master's Theses by an authorized administrator of SJSU ScholarWorks. For more information, please contact scholarworks@sjsu.edu. 
GEOGRAPHIC VARIATION IN THE LIFE HISTORY AND MORPHOLOGY OF THE PACIFIC GEODUCK, PANOPEA GENEROSA

\author{
A Thesis \\ Presented to \\ The Faculty of the Department of Marine Science \\ San José State University \\ In Partial Fulfillment \\ of the Requirements for the Degree \\ Master of Science
}

by

Gabriela Navas

December 2015 
(C) 2015

Gabriela Navas

ALL RIGHTS RESERVED 
The Designated Thesis Committee Approves the Thesis Titled GEOGRAPHIC VARIATION IN THE LIFE HISTORY AND MORPHOLOGY OF THE PACIFIC GEODUCK, PANOPEA GENEROSA

by

Gabriela Navas

APPROVED FOR THE DEPARTMENT OF MARINE SCIENCE SAN JOSÉ STATE UNIVERSITY

December 2015

Dr. Scott Hamilton

Dr. Jonathan Geller

Dr. Brent Vadopalas
Moss Landing Marine Laboratories

Moss Landing Marine Laboratories

University of Washington 


\title{
ABSTRACT \\ GEOGRAPHIC VARIATION IN THE LIFE HISTORY AND MORPHOLOGY OF THE PACIFIC GEODUCK, PANOPEA GENEROSA
}

\author{
by Gabriela Navas
}

The Pacific geoduck, Panopea generosa, is an ideal candidate to investigate patterns of life history variation and morphological plasticity in shell shape, as it occurs over a large geographic range, inhabits different marine environments, and experiences intense fishing pressure in some locations (i.e., Mexico and Washington). Six populations were sampled from Washington to Mexico to evaluate evidence for geographic variation in demography, life history, and morphology. Results provided evidence for a latitudinal cline with larger clams occurring in locations characterized by colder water temperature. Age structure and longevity analyses indicated that life expectancy was significantly lowered at intertidal sites compared to subtidal sites, potentially in response to fishing. Von Bertalanffy growth model (VBGM) analyses revealed significant spatial variation in asymptotic lengths across sampling locations. Correlations of climate (temperature and chlorophyll a) and growth parameters indicated that clams reached larger sizes at locations that were cooler and more productive. Morphological analyses revealed significant spatial differences that did not follow a latitudinal pattern, but may be better explained by site-specific habitat differences. Results will aid managers in developing regulations, tuned to the demographic variability present along the eastern Pacific coast. 


\section{ACKNOWLEDGEMENTS}

However insurmountable a project may seem, with the help of great mentorship and an amazing team, anything is possible. I have been blessed with one of the best mentors and advisors a student could wish for. Dr. Scott Hamilton has been essential in making me believe that I too can be a real Scientist. I have struggled and overcome many academic challenges in the past four years, but Scott has always been there to support me. Henry Ford once said: "Obstacles are those frightful things you see when you take your eyes off your goals." Well, Scott, thank you for always getting me refocused on my goals! I will always remain grateful for your advisorship. I would like to thank my committee member Jon Geller for accepting me into the MLML program and his expertise in Invertebrate Zoology. Words cannot describe my gratitude to my committee member Brent Vadopalas. Brent, you have encouraged me to present my research at conferences and taught me so much about geoducks. My thesis project took on new dimensions, literally, because of your encouragement. Prior to my commencing my academic career at MLML I was under the impression that geoducks were waterfowl. I would like to thank Kai Lampson for introducing me to this long-lived burrowing clam and the need for understanding population dynamics in California. I would also like to thank Ignacio Leyva-Valencia, Chris Klingenberg, and Dave Sheets for opening my eyes to the world of geometric morphometrics and shape analysis. The Washington Department of Fish and Wildlife sponsored me to learn their aging 
techniques, and I will always cherish my time there. Thank you Bob Sizemore and Bethany Stevick for allowing me to spend three weeks in your aging lab in Olympia. Fieldwork was a large portion of my thesis, which was accomplished with the help of many hard-working and fearless colleagues at MLML and the CA Department of Fish and Wildlife. I will always appreciate and remember fondly the early mornings and seemingly endless hours of sampling and processing that Marilyn Cruickshank, Emily Donham, Catherine Drake, Sarah Jeffries, Josh Jones, Kai Lampson, Stephen Loiacono, Michelle Marraffini, Carlos Mireles, Jasmine Ruvalcaba, Drew Seals, Derek Stein, Andrea Valdez, Melinda Wheelock, Alan Wood, Tim Wood, and Sara Worden were part of. I have learned so much about programming from Ryan Fields, Stephanie Flora, Bobby San Miguel, and Angela Szesciorka. I would also like to thank my funding sources that enabled me to purchase equipment and pay for travel expenses. I was the fortunate recipient of the Council on Ocean Affairs, Science, and Technology (COAST) grant, the Dr. Earl H. and Ethel M. Myers Oceanographic and Marine Biology Trust, the David and Lucile Packard Foundation, the MLML Wave Scholarship, and was funded partly by the National Shellfisheries Association - Pacific Coast section to present at conferences. Some key people facilitated some of the equipment and travel needed for my thesis. My deepest felt thanks for all their logistical support goes to Gary Adams, Billy Cochran, James Cochran, Jocelyn Douglas, Brynn Kaufmann, Chris Machado, and JD. Last, but definitely not least, I would like to thank my family for supporting me in 
this endeavor. I am a first generation immigrant and college graduate, and have been kindly adopted as family by many in this country. Some of these have enabled me to keep going and pursue my dream. Amy Jones and Dina Pielaet, your encouragement has been essential in my academic career, and I will always appreciate you making me part of your family. Thank you Josh Jones, my dear son, for supporting me during these last four years. You have been truly a joy to be around, and I am so proud to be your mother. Alan Wood, you are the best companion anyone can wish for. Thank you for joining me on every sampling trip and always encouraging me to keep going. You truly are an inspiration to me. This thesis is dedicated to Alan Wood and Josh Jones. I am looking forward to the next chapter in our lives together. 


\section{TABLE OF CONTENTS}

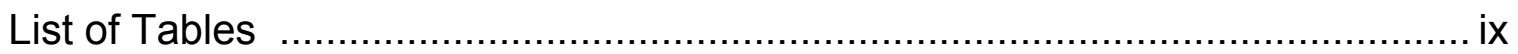

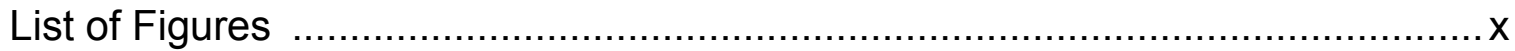

Introduction

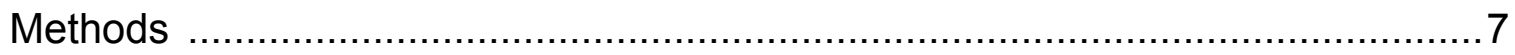

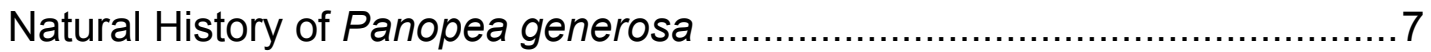

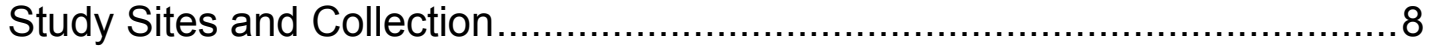

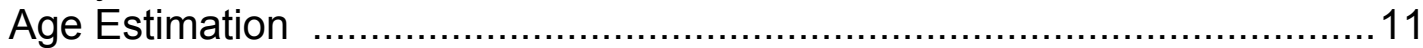

Lifetime Growth Curve Estimation ......................................................13

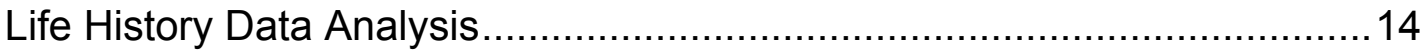

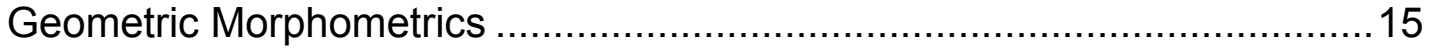

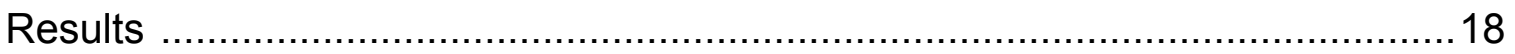

Geographic Variation in Size Structure and Condition .............................18

Age, Growth, and Environmental Correlates .........................................26

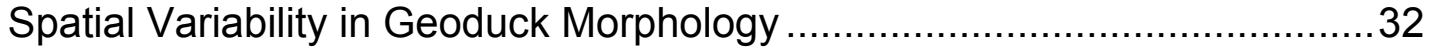

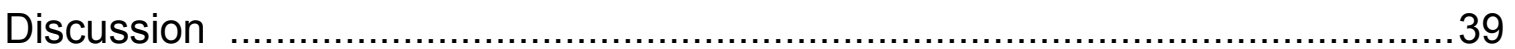

Geographic Variation in Size Structure and Condition ...............................39

Age, Growth, and Environmental Correlates ........................................42

Spatial Variability in Geoduck Morphology ..........................................46

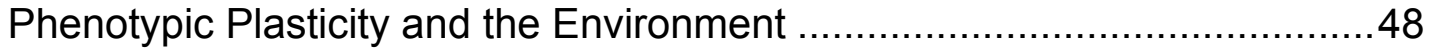

Recommendations for Fishery Management.........................................49

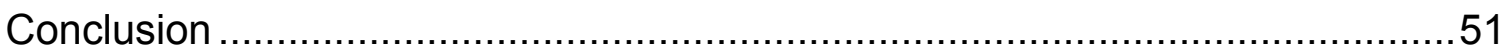

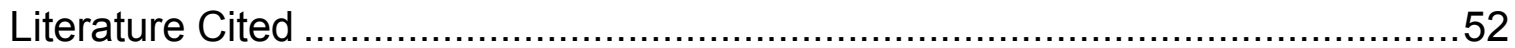




\section{LIST OF TABLES}

Table 1. Collection site information for all study sites

Table 2. Life history parameters for 5 sites. $L_{\text {inf }}$ and $K$ refer to the von Bertalanffy growth model parameters fitted to the age-at-size data at each site. Values represent the mean $\pm 95 \% \mathrm{Cl}$. Sites are denoted with an "(s)" for subtidal and an"(i)" for intertidal

Table 3. Whole weight $(\mathrm{g})$ and valve length $(\mathrm{mm})$ nonlinear regression power fit results for 5 sites. Sites are denoted with an "(s)" for subtidal and an"(i)" for intertidal

Table 4. Shape variation among groups, scaled by the inverse of the within-group variation

Table 5. Mahalanobis distances measured in Procrustes distance among groups ( $p$-values <.0001 from 10,000 rounds permutation tests). Each site is denoted with an "(s)" for subtidal and an "(i)" for intertidal

Table 6. Procrustes distances among groups ( $p$-value <.0001 after 10,000 round permutation test for all sites, with exception of Morro Bay and Bodega Bay, p-value $=0.0197$ ). Each site is denoted with an "(s)" for subtidal and an "(i)" for intertidal 


\section{LIST OF FIGURES}

Figure 1. Map of six collection sites included in this study. Sample sizes are in parentheses

Figure 2. Aging methods. A. Sectioning of umbo. B. Sections mounted on slide. C. Polishing. D. Aging of acetate peel (each numbered increment represents one year of growth from youngest to oldest). This slide shows a 13-year-old geoduck section.

Figure 3. Landmark placement in geoduck shells in Image J. 15 landmarks (red) were placed in and around shell at the same location for each shell

Figure 4. Geoduck whole weight (top graph) and valve length (bottom graph) comparisons by site. Boxes represent quartiles. The dots next to the boxes are the raw data points for each site. The horizontal dotted line in each box indicates site mean value. The solid horizontal line indicates the median of the site data. No whole weight data were available for San Quintin, Mexico. The Tukey HSD post-hoc test results are shown as lower case letters above boxes. All means are significantly different if they are not sharing any letters. Each site is denoted with an "(s)" for subtidal and an "(i)" for intertidal..

Figure 5. Length-weight relationships for geoducks from 5 study locations. A) Dungeness West, WA; B) Bodega Bay, CA; C) Morro Bay, CA; D) Santa Cruz Island, CA; E) Catalina Island, CA. Each site is denoted with an "(s)" for subtidal and an "(i)" for intertidal

Figure 6. Fulton's body condition factor $(K)$ averages by site. Error bars represent $\pm 95 \% \mathrm{Cl}$. The Tukey HSD post-hoc test results are shown as lower case letters above bars. Means not sharing the same letters are significantly different. Each site is denoted with an "(s)" for subtidal and an "(i)" for intertidal.

Figure 7. Age-frequency distributions of geoducks for five of the sampling locations in California and Washington. Note: age classes are binned in 10-year increments. Each site is denoted with an "(s)" for subtidal and an "(i)" for intertidal.

Figure 8. Longevity means for 5 sites (mean of top quartile of clam ages, $\pm 95 \% \mathrm{Cl}$ ). The Tukey HSD post-hoc test results are shown as lower case letters above bars. Means with same letters are not significantly different. Each site is denoted with an "(s)" for subtidal and an "(i)" for intertidal 
Figure 9. Geographic variation in lifetime growth curves of geoducks from 5 study locations (A-E). Each site is denoted with an "(s)" for subtidal and an "(i)" for intertidal. Von Bertalanffy growth model (VBGM) were fit to length-at-age data for each site (solid line) and $\pm 95 \% \mathrm{Cl}$ (dashed lines). VBGM curves for each site superimposed $(F)$.

Figure 10. Von Bertalanffy growth parameters for each study location. Error bars represent $\pm 95 \% \mathrm{Cl}$. Each site is denoted with an "(s)" for subtidal and an "(i)" for intertidal ....

Figure 11. Relationships between geoduck life history variables and regional environmental conditions (A-D). Von Bertalanffy growth parameters for 5 sites compared to ten-year averages (2002-2012) of sea surface temperatures $\left(\mathrm{SST},{ }^{\circ} \mathrm{C}\right)$ and chlorophyll a $\left(\mathrm{Chl} a, \mathrm{mg}^{*} \mathrm{~m}^{-3}\right)$ levels.

$\mathrm{WA}=$ Dungeness West, WA, BOD= Bodega Bay, CA, MOR= Morro Bay, CA, SCI= Santa Cruz Island, CA, $\mathrm{CAT}=$ Catalina Island, CA

Figure 12. Each point represents the shape of a clamshell. Sites are denoted by colors. Intertidal and subtidal sites are marked by "(i)" and "(s)" respectively. The zero point of each axis denotes the grand average of all sites. Canonical Variate 1 (CV1) axis explains $52.3 \%$ of the variation in shell shape and represents the degree of dorso-ventral compression of a shell. Canonical Variate 2 (CV2) explains $20.9 \%$ of the variation in shell shape and represents the degree of antero-posterior variation in a shell. The ellipses represent the $90 \%$ confidence intervals for each site

Figure 13. (A-E) Log Centroid Size versus Shape Score. All sites with the exception of Catalina Island $(p=0.02, r=0.48)$ show that Centroid Size is not a predictor of shape. Each site is denoted with an "(s)" for subtidal and an "(i)" for intertidal.

Figure 14. (A-E) Residual shape scores from Fig. 13 (shape versus centroid size) were used to evaluate age as a predictor of shape irrespective of any possible allometric (size) effects inherent in shape. Each site is denoted with an "(s)" for subtidal and an "(i)" for intertidal. 


\section{Introduction}

Populations of marine species have been shown to differ in demographic life history, and morphological traits across a variety of temporal and spatial scales (Caley et al. 1996; Agrawal 2001; Kinlan et al. 2005; Longhurst 2007; Thorson 2015). By expressing phenotypic plasticity, biological traits of populations can be altered to better match the selective pressures experienced. Numerous studies on fishes and invertebrates have shown that life history traits such as timing of maturation, growth, age structure, and recruitment can vary widely across a species' range in response to environmental gradients, interspecific competition, prey availability, predation, and fishing pressure (Connell 1961; Hagen and Gilbertson 1972, 1973; Fleming and Gross 1990; Tollrian 1995; Armstrong et al. 1998; Begg et al. 1999; Straile and Hälbich 2000; Blanckenhorn and Demont 2004; Loher and Armstrong 2005; Hamilton et al. 2007; Caselle et al. 2011).

Previous studies have reported that demographic and life history traits respond to gradients in environmental conditions, such as temperature, productivity, irradiation, and wave exposure. Individuals often attain larger sizes and older ages at higher latitudes, where waters are cooler and more productive (Lindsey 1966; Caselle et al. 2011). This pattern is called Bergmann's rule (Bergmann 1847), and past studies have provided support for this phenomenon in both terrestrial and marine systems (Watt et al. 2010; Daufresne et al. 2013). Other studies have highlighted that temperatures, independent of latitude, drive 
life history variation in fish (Ruttenberg et al. 2005). For photosynthetic organisms, the amount of irradiation experienced with changing latitudes can strongly influence growth (Harvey 1942). Wave exposure may also influence longevity and patterns of growth in marine organisms (Dayton 1971; Denny et al. 1985; Etter 1989). In addition, other environmental variables, such as habitat composition can cause changes in life history and demographic traits over a variety of scales (Robertson et al. 2005). Variability in ecological conditions experienced by marine populations has also been shown to result in shifts in life history and demographic traits. For example, increased predation risk may alter the timing of sex change (DeMartini et al. 2005) and alter patterns of longevity, growth, and body condition in coral reef fishes (Ruttenberg et al. 2005; Walsh et al. 2012).

Species harvested across large geographic scales often exhibit significant shifts in life history and demographic traits in response to size-selective harvesting pressure (Law 2000; Hutchings 2005; Hamilton et al. 2007). Past studies have shown that fishing can alter size and age structure (Conover and Munch 2002), growth rates (Enberg et al. 2012), sex ratios (Jivoff 2003), timing of maturation (Jørgensen 1990; Hutchings 2005; Law 2007), and sex-change (Hamilton et al. 2007; Fenberg and Roy 2012). Shifts in these key demographic traits may lead to changes in reproductive output, which could negatively impact fitness and resource sustainability in the future. Understanding the scales of variability among population traits is therefore an important aspect of fisheries 
that needs to be incorporated more robustly in the management of harvested species (Gunderson et al. 2008).

Prior studies have also shown that organismal body form or morphology can differ greatly among populations (Galdecutt et al. 1998; Klingenberg et al. 2003; Trussell 2000; Costa et al. 2008; Almeland 2015). Potential ecological and environmental drivers of spatial differences in organismal body shape include but are not limited to predator avoidance (Hagen and Gilbertson 1973; Bourdeau 2011), competition for resources (Relyea and Auld 2005), environmental stress such as desiccation, or thermal exposure (Miller and Denny 2011; Gleason and Burton 2013), and variability in habitat structure and composition (Chan 2001; Pulcini et al. 2008). Parasites have also been reported to induce morphological changes in their hosts (Hoffmann 1956; Miura et al. 2006).

The development of geometric morphometric techniques (Bookstein 1978, 1991, 1996, 1998; Bookstein et al. 1985; Adams et al. 2013) led to rapid advances in quantifying organismal form (Reyment et al. 1984; Rohlf and Marcus 1993; Kendall et al. 1999). The development of analytical techniques (i.e., Generalized Procrustes Superimposition, Rohlf and Marcus 1990) to isolate the effects of shape, independent from potential confounding factors such as size, orientation, and translocation, revolutionized the field. Computationally intensive statistical methods (Dryden and Mardia 1998; Lele and Richtsmeier 2001; Zelditch et al. 2012) accompanied these techniques to address ecomorphological questions in many different systems (Pimentel 1979; Small 1996). 
Geoducks are an ideal study species to investigate geographic variation in life history and morphology. The Pacific geoduck, Panopea generosa Gould 1850 (formerly Panopea abrupta Conrad 1849 Vadopalas et al. 2010), is found in intertidal to subtidal soft substrates from Alaska to Baja California (Anderson 1971; Bernard 1983; Goodwin and Pease 1987; Coan et al. 2000; LeyvaValencia et al. 2012; González-Pelàez et al. 2013). This clam is one of the largest burrowing bivalves in the world with a siphon length of up to $1 \mathrm{~m}$, allowing it to burrow deep into the sediment. $P$. generosa can reach ages of over 150 years, which make them suitable for longevity and life history studies (Bureau et al. 2002; Black et al. 2008; Black 2009). Recent studies have used a geoduck's plastic shell morphology to distinguish within species variation in P. globosa and among species variation between the north Pacific species, $P$. generosa, and the Mexican species, P. globosa (Leyva-Valencia et al. 2012). Studies on morphology (shell shape) of other bivalves have reported evidence for shell plasticity in response to environmental variation such as substrate type, water quality, and ambient temperature (Ferson et al. 1985; Innes and Bates 1999; Palmer et al. 2004; Costa et al. 2008).

Geoducks are a highly prized delicacy in international markets and support commercial and recreational fisheries along the Pacific coast of North America. Increasing demand mainly from Asian markets has been sustained by augmenting the wild fishery with aquaculture of $P$. generosa (Welch 2012). According to the Washington Department of Fish and Wildlife (WDFW) the wild 
geoduck fishery generates about $\$ 22$ million in revenue for the state every year (WDFW 2013). In 2002, Mexico launched its geoduck fishery, targeting both $P$. generosa and $P$. globosa, and it is surpassing Washington State revenues with wild fishery harvest (Rocha-Olivares et al. 2010; Aragón-Noriega et al. 2012). While there is no commercial take of $P$. generosa in California, a recreational fishery exists despite the paucity of data relevant to management. Surveys conducted by the California Department of Fish and Wildlife (CDFW) indicate that geoduck populations are abundant at certain sites along the California coast (unpublished data).

To better understand $P$. generosa population demography and dynamics in California, and more broadly across its range, studies are necessary to assess the scales of natural population variability and the potential environmental correlates of that variation. Population genetic analyses using mitochondrial DNA and microsatellite markers indicate that the population of $P$. generosa appears to be generally panmictic throughout its range, with chaotic genetic patchiness (Vadopalas et al. 2004; Suarez-Moo 2012; Vadopalas et al. 2012). However, Miller et al. (2006) studied P. generosa populations in British Columbia, and found significant geographic structure following an isolation-by-distance pattern using eight microsatellite loci. Given the lack of high resolution on population genetic structure on a large spatial scale, I was interested in evaluating whether life history, demographic, and morphometric traits exhibited any geographic structure in this species. Phenotypic plasticity is a potential 
mechanism that could explain how life history and morphological traits can change spatially, in response to local environmental and ecological conditions, even in the face of high gene flow (Koehn et al. 1976; Sanford and Kelly 2011).

The goal of this study was to examine spatial differences in life history traits of $P$. generosa from Washington, California, and Mexico. I collected and analyzed data on life history and morphological parameters to aid in the biological assessment efforts over a large portion of the geographic range of $P$. generosa. My objective was to investigate how specific life history traits, including mean weight, mean valve length, age, longevity, and body condition differed among populations across the species' range. I related long-term data on sea surface temperatures (SST) and Chlorophyll a (Chl a) at each sampling location with lifetime growth parameters to identify whether growth varied as a function of either environmental factors or latitude. In addition, I used geometric morphometric tools to identify geographic differences in morphology or shell shape. Shape differences might arise due to age (i.e., as a clam gets older, its shell shape could change) or the environmental and habitat conditions experienced at a particular site over time (e.g., the Atlantic Herring Clupea harengus, Libungan et al. 2015; the mussels Mytilus edulis and M. trossulus, Innes and Bates 1999). Overall, I hypothesized that site-specific life history traits and morphological differences of $P$. generosa would be driven by phenotypic plasticity in response to environmental gradients and exposure to harvesting. 


\section{Methods}

\section{Natural History of Panopea generosa}

The Pacific geoduck, Panopea generosa, is a member of the bivalve family Hiatellidae, known to inhabit soft substrates such as sand, mud, gravel, and mixed loose substrates (Ricketts et al. 1968; Goodwin and Pease 1991). P. generosa ranges from southeast Alaska to northern Baja California, Mexico (Anderson 1971; Bernard 1983; Goodwin and Pease 1987; Coan et al. 2000; Leyva-Valencia et al. 2012; González-Pelàez et al. 2013), where appropriate habitat occurs in exposed coastal mainland and island areas, to protected bays, estuaries, and inland seas. These long-lived clams (the oldest aged clam, to date, was 168 years old; Bureau et al. 2002) are broadcast spawners that release their gametes into the water column. Recent studies show that environmental sex determination plays a substantial role in sex ratios, with clams maturing as early as two years of age (Campbell and Ming 2003; Vadopalas et al. 2015). Fertilization occurs in the late spring and summer months (Sloan and Robinson 1984; Campbell and Ming 2003). The subsequent planktonic stage develops in the water column for up to 47 days at $14^{\circ} \mathrm{C}$ (Goodwin et al. 1979) prior to settling onto a suitable substrate. Suitable depths range from the low intertidal zones to $110 \mathrm{~m}$ (Jamison et al. 1984). Geoducks burrow into the sediment up to a vertical depth of $1 \mathrm{~m}$, remaining there for the rest of their lives, with very little movement thereafter. They filter water through their in- and excurrent siphons, with an estimated filtration rate of 7-20 L per hour per individual 
(Straus et al. 2008).

Coan et al. (2000) described the valves of $P$. generosa shells as having a continuous pallial line with a deep pallial sinus, inner margins that are smooth, one singular cardinal tooth, an external ligament, and a porcelaneous interior. The two adductor muscle attachment sites are similar in shape. Each shell half is comprised of a hinge plate and consists of three layers. These layers, produced by accretionary growth, can be used to estimate $P$. generosa's age, growth rates, age-frequency distributions, and construct lifetime growth curves (Shaul and Goodwin 1982; Breen and Shields 1983; Goodwin and Shaul 1984; Sloan and Robinson 1984; Campbell and Ming 2003; Gribben 2005; Black et al. 2008; Calderon-Aguilera et al. 2010a; Bautista-Romero et al. 2015; Hidalgo-DeLa-Toba et al. 2015). Reported average valve lengths of $P$. generosa range from 114 mm to 139 mm (Goodwin and Pease 1991; Rocha-Olivares et al. 2010; Hidalgo-De-La-Toba et al. 2015), with the largest lengths observed in British Columbia (Bureau et al. 2002). Average weights of $P$. generosa range from 512 $\mathrm{g}$ to $1,510 \mathrm{~g}$, with the heaviest clams found in British Columbia (Goodwin and Pease 1987; Bureau et al. 2002; Rocha-Olivares et al. 2010; Hidalgo-De-LaToba et al. 2015).

\section{Study Sites and Collection}

Geoducks for this study were collected between 2011-2014 at each of four sites in California (two subtidal and two intertidal sites; CDFW Permit \# 9042; 
Table 1; Fig.1). Subtidal California clams (Catalina Island in 2011, and Santa Cruz Island in 2013) were collected haphazardly using SCUBA and a water pressure hose that liquefied the sediment surrounding a clam. Intertidal clams (Bodega Bay in 2013 and 2014, and Morro Bay in 2014) were collected using three-foot long PVC pipes to mark burrows, and shovels to dig up clams. Geoduck samples from Washington and Mexico were obtained from colleagues.

Table 1. Collection site information for all study sites.

\begin{tabular}{|l|l|l|l|l|}
\hline \multicolumn{1}{|c|}{ Site } & \multicolumn{1}{|c|}{ Latitude } & \multicolumn{1}{c|}{ Longitude } & Depth $(\mathrm{m})$ & $\mathrm{n}$ \\
\hline Dungeness West, WA & $48^{\circ} 08.227^{\prime} \mathrm{N}$ & $123^{\circ} 15.195^{\prime} \mathrm{W}$ & $11-21$ & 36 \\
\hline Bodega Bay, CA & $38^{\circ} 19.262^{\prime} \mathrm{N}$ & $123^{\circ} 03.222^{\prime} \mathrm{W}$ & intertidal & 30 \\
\hline Morro Bay, CA & $35^{\circ} 20.606^{\prime} \mathrm{N}$ & $120^{\circ} 50.665^{\prime} \mathrm{W}$ & intertidal & 50 \\
\hline Santa Cruz Island, CA & $34^{\circ} 03.236^{\prime} \mathrm{N}$ & $119^{\circ} 49.054^{\prime} \mathrm{W}$ & $9-12$ & 37 \\
\hline Catalina Island, CA & $33^{\circ} 25.503^{\prime} \mathrm{N}$ & $118^{\circ} 30.427^{\prime} \mathrm{W}$ & $18-24$ & 32 \\
\hline San Quintin, Mexico & $30^{\circ} 23^{\prime} \mathrm{N}$ & $115^{\circ} 57^{\prime} \mathrm{W}$ & $8-15$ & 30 \\
\hline
\end{tabular}




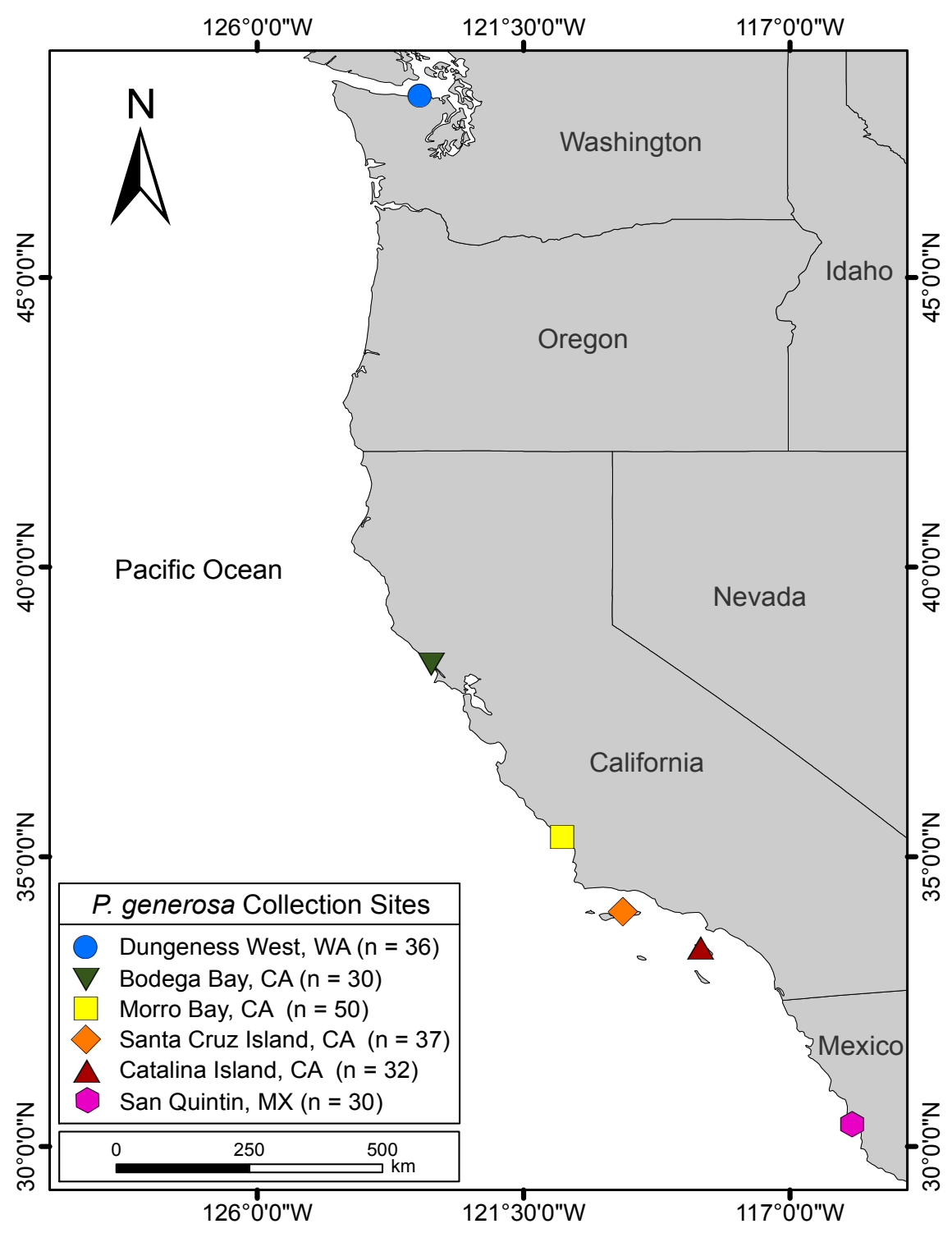

Figure 1. Map of 6 collection sites included in this study. Sample sizes are in parentheses.

Geoducks were kept in filtered seawater aquaria at Moss Landing Marine Laboratories, Moss Landing, California, until processing. To record basic morphometric variables of the clams, whole wet weight $(\mathrm{g})$ was recorded using a precision electronic balance and valve length $(\mathrm{mm})$ was measured using calipers. 
Length and weight data were used to examine geographic variation in lengthweight relationships and condition indices. Two $0.5 \mathrm{~cm}^{3}$ pieces of tissue from the siphon were dissected, one piece was preserved in $95 \% \mathrm{EtOH}$, the other was frozen at $70^{\circ} \mathrm{C}$. Tissues were preserved for future genetic studies.

The Washington Department of Fish and Wildlife (Bethany Stevick, WDFW) provided aged samples (collected in 2012) and corresponding shell images for age-frequency class distribution comparisons and morphological analyses from Dungeness West, WA. Ignacio Leyva-Valencia (Centro de Investigaciones Biológicas del Noroeste, Mexico) provided shell images from San Quintin, Mexico (collected in 2010). Images of shells from Mexico were used for shell shape and valve length comparisons to all other sites, but age data could not be inferred.

\section{Age Estimation}

Individual clams from each population were aged in order to obtain information on age structure, growth rates, and longevity. All shells were cut into squares using a small air-compression handsaw, while keeping the umbo intact.

Ages were estimated at the four collection sites in California according to methods validated by Vadopalas et al. (2011). The steps involved in aging California samples included cutting the hinge plate (where the right and left shell valves meet) of the geoduck shell at the umbo where layers of shell are added with each subsequent year starting at the end of the first year. Sectioning of the 
umbo allowed for quantification of these yearly layers, which comprise the age rings or annuli (similar to tree rings, Fig. 2). To section the clamshells, the hinge plate of a clam was placed on a diamond blade attached to an "Isomet" (Buehler, Model \# 111280) slow-speed saw with a modified chuck to keep the hinge plate from moving. Four thin sections were cut, two at the umbo, one midway, and another closest to the hinge plate edge for replication keeping thin sections at constant distances roughly $0.6 \mu \mathrm{m}$ apart. Then, the four sections per clam were glued onto a microscope slide using 2-3 drops of "Cytoseal 60" (Thermo Scientific, Catalog \# 23-244257) slide preparation glue. Slides were left to dry for 24 hours prior to polishing them using 300 grit and 600 grit sand paper with a rotating polishing machine (Isomet 3) at 200-300 RPMs.

To enhance ring clarity prior to aging, polished slides were etched in a $1 \%$ $\mathrm{HCL}$ bath for 2 minutes. Acetate peels were taken using the methods developed by Shaul and Goodwin (1982). Peels were centered between two glass slides and the edges were taped to secure the peels. Prepared peels were then placed under a Leica DM4000 compound microscope (4x and 10x magnifications), and samples were aged using annual growth increment counts and the program ImagePro Plus v.7.0. Cross-dating, based on tree-ring analysis, was employed to increase accuracy (Black et al. 2008). The assumption of the cross-dating method is that environmental variability is the same for each geographic region allowing for an organism to feature synchronized growth patterns, which are manifested in the growth ring increments. 

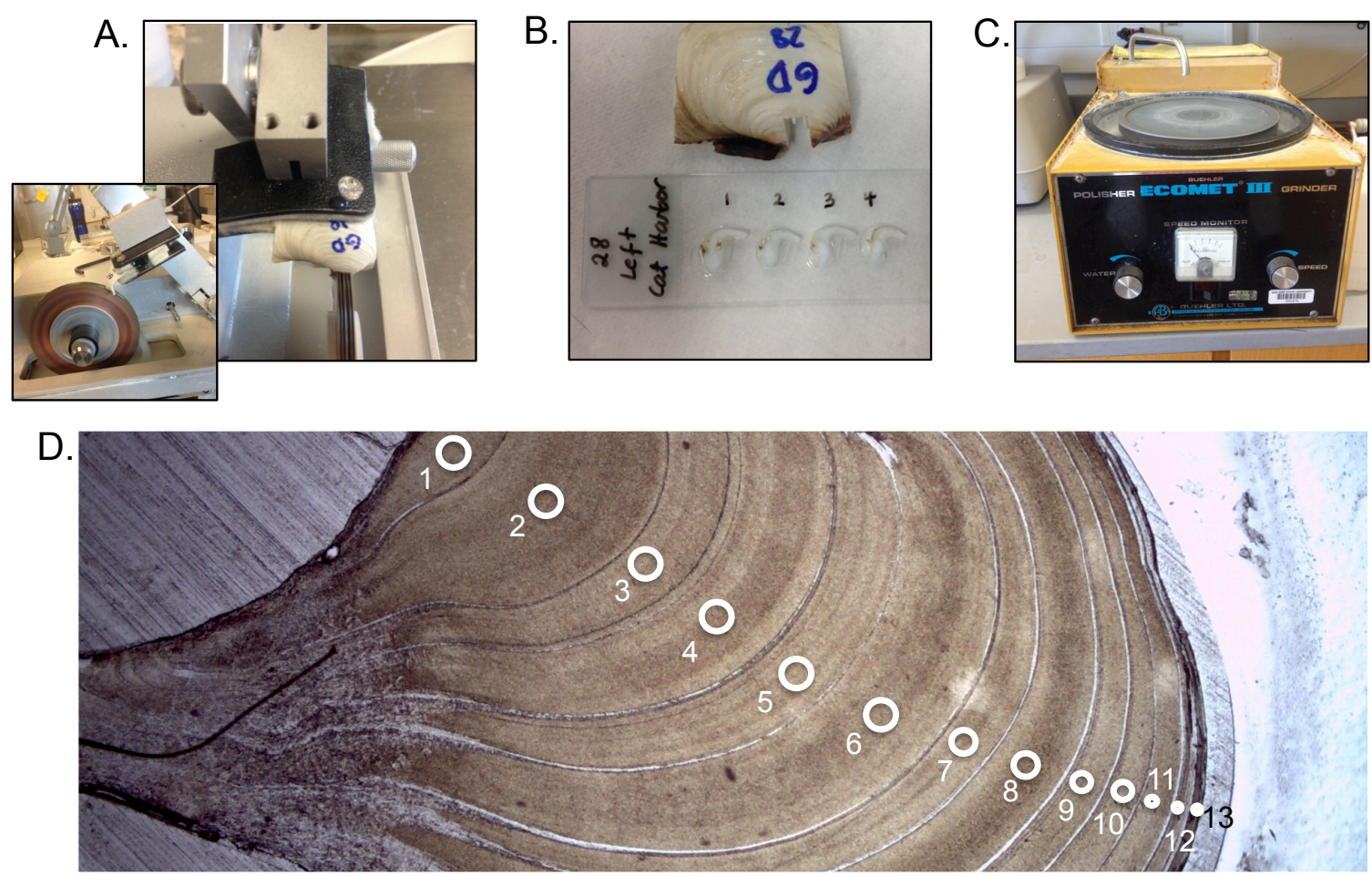

Figure 2. Aging methods. A. Sectioning of umbo. B. Sections mounted on slide. C. Polishing. D. Aging of acetate peel (each numbered increment represents one year of growth from youngest to oldest). This slide shows a 13-year-old geoduck section.

\section{Lifetime Growth Curve Estimation}

In order to construct lifetime growth curves for each population, length and age data were fit to the von Bertalanffy growth model (VBGM) equation, as modified from the Fisheries R vignette (Ogle 2015). VBGM equations were adjusted according to the description by Pérez-Valencia and Aragón-Noriega (2013) on P. globosa to visualize length-at-age clam data using:

$$
\mathrm{L}(\mathrm{t})=\mathrm{L}_{\mathrm{inf}}\left(1-\mathrm{e}^{-K\left(\mathrm{t}-\mathrm{t}_{0}\right)}\right)
$$

Where $L(t)$ represents the predicted valve length of the clam shell at age $(t), L_{\text {inf }}$ 
represents the predicted maximum asymptotic length parameter, $K$ is the coefficient of growth or the curvature parameter (how fast $L_{\text {inf }}$ is reached), $t$ represents the clam's age, and $t_{0}$ is the hypothetical age, at which a clam had zero length (initial condition parameter). Following recommendations in Robertson et al. (2005) to was fixed to zero for each population, due to the extreme difficultly in finding young individuals.

To test whether growth curves were significantly different from each other among sampling locations, two approaches were used. First, 95\% Confidence Intervals were calculated around the model fit for the growth curve for each sampling location. Secondly, 95\% confidence intervals were compared for the two most important growth equation parameters, $\mathrm{L}_{\text {inf }}$ and $K$, in bivariate space. In both cases, lack of overlap of growth curves or curve parameters signified statistical significance at the $\alpha=0.05$ level.

\section{Life History Data Analysis}

Length-weight relationships were fit using a non-linear power function for each population and length-weight parameters were compared among populations using an analysis of variance (ANOVA), followed by a Tukey posthoc analysis to identify how sites differed from one another. As a proxy for condition, the Fulton's K condition factor was calculated (Ricker 1975) using the equation $\mathrm{W} / \mathrm{L}^{3} \times 1000$, and compared among the populations using an analysis of variance (ANOVA). 
Size-frequency and age-frequency distributions were compared among geographic locations using an ANOVA to test whether mean size or age differed geographically. Longevity was calculated as the top quartile of the age distribution for each location (i.e., $\mathrm{T}_{\max }$; sensu Choat and Robertson 2002), which corrects for bias in estimating the maximum age for small and unequal sample sizes.

In order to examine whether life history traits correlated with long-term mean environmental conditions present at each sampling location, sea surface temperature (SST) and chlorophyll a (Chl a) data for a 10-year period were obtained. SST and Chl a data were acquired from satellite remote sensing data (AVHRR Pathfinder and MODIS) maintained by the Giovanni online data system through NASA GES DISC (2015). Briefly, SST and Chl a were averaged over a $4 \mathrm{~km}$ box offshore for each sampling region for the 10-year period from 2002 to 2012. Chl a and temperature were tested independently to examine their relative influence on life history traits (e.g., longevity, Linf, and $K$ ) despite obvious autocorrelation of these two variables.

\section{Geometric Morphometrics}

Prior to estimating ages of California samples, shell halves were cleaned, dried, and numbered. The internal scars of each shell were traced with a lead pencil to enhance internal scars in photographs. To examine geographic variability in shell morphology, high-resolution images were taken with a Nikon 
D3100 macro lens placed on a tripod for stability highlighting three anatomical features in geoduck shells: the umbo, antero-ventral adductor muscle scar, and postero-ventral pallial sinus scar. These features have been shown to best characterize morphological differences in geoduck clams (Leyva-Valencia et al. 2012). Clamshell pictures were imported into Image J (Schneider et al. 2012) and 15 landmarks were placed on each shell, capturing the anatomical features discussed above (Fig. 3). Each landmark's position was noted as x-and ycoordinates per landmark for a total of 30 coordinates and 15 landmarks per shell. Morphometric landmark data from Image $\mathrm{J}$ were then imported into the shape analysis program Morpho J v.1.06d (Klingenberg 2011). Morpho J was used to compare the landmark positions on each shell in geometric space via Generalized Procrustes Superimposition (Kendall 1977; Rohlf and Slice 1990; Goodall 1991). 
DORSAL REGION

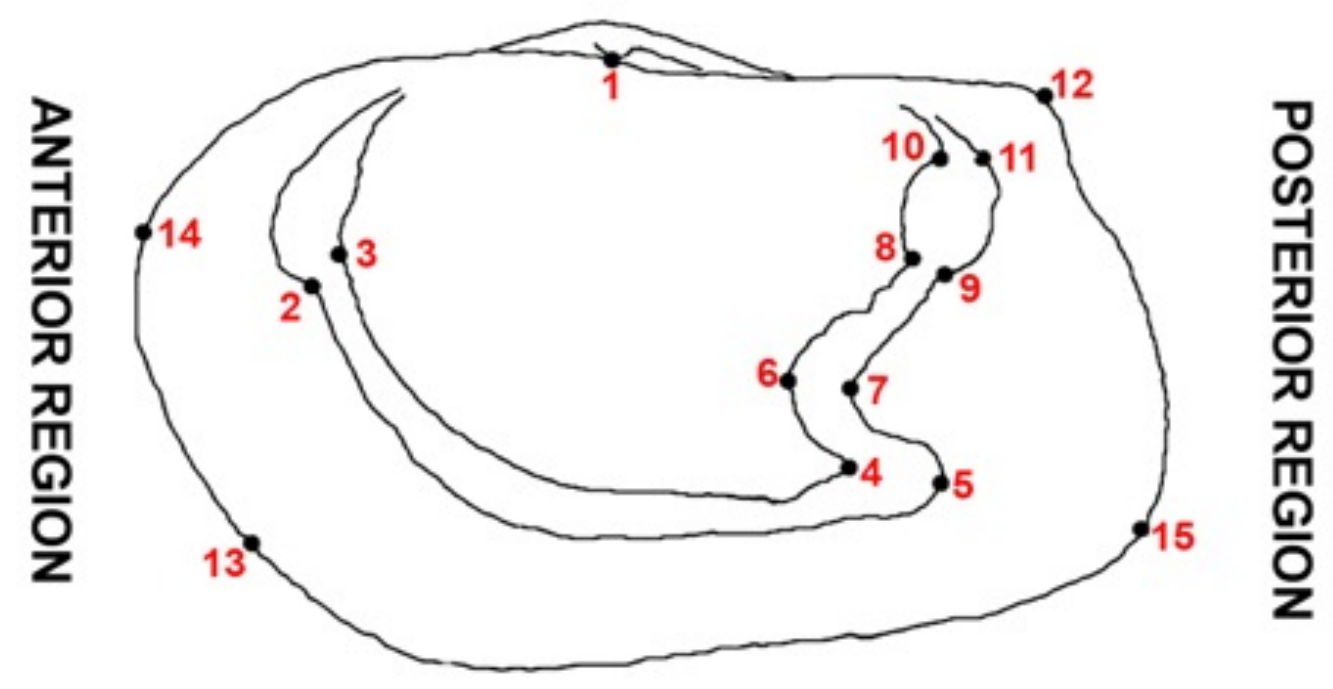

VENTRAL REGION

Figure 3. Landmark placement in clam shells in Image J. 15 landmarks (red) were placed in and around shell at the same location for each shell.

Three steps were involved to superimpose clamshells in shape space (Bookstein 1991): First, location differences (translocation) of the clam valve in each picture were removed by generating a reference coordinate system $(0,0)$ in Cartesian space. Second, shell valves were rescaled geometrically upon their centroid size (the square root of the sum of squares distances of each landmark), and third, the orientation of clamshells was synchronized. Composite shell shape differences were then compared among sampling locations using a multivariate canonical variates analysis (CVA), which seeks to maximize within and among site variation in shape. 
To test whether shell morphology differed significantly among sampling locations, 90\% confidence ellipses were calculated around each site and significance was determined by the lack of overlap. Confidence intervals were calculated using resampling techniques by bootstrapping the site-specific distribution of shell shape variation 10,000 times with replacement. Lastly, shell morphology changes at each site as a function of clam age, after controlling for differences in shape due to size, were analyzed. Shape Regression scores were assigned to each shell using the Procrustes distances (Euclidean distance between each $\mathrm{x}$-and $\mathrm{y}$-coordinate for all 15 landmarks per shell). These shape scores were then regressed against the centroid size of each shell (i.e., a dimensionless proxy of organism size) to eliminate allometric effects on shape. Residuals from this regression were saved and correlated with age at each site to test whether age (irrespective of any inherent size parameter) was associated positively or negatively with shell shape metrics.

\section{Results}

\section{Geographic Variation in Size Structure and Condition}

Geoducks exhibited significant spatial differences in whole weight (ANOVA, $F_{4,179}=61.98, p<.0001 ;$ Table 2; Fig. $4 A$ ) and valve length (ANOVA, $F_{5,208}=46.52, p<.0001 ;$ Table 2; Fig. 4B) among sampling locations. There were no whole weight data available for San Quintin, MX. The Tukey HSD post-hoc results showed that geoducks differed in whole weight and valve length (Fig.4) 
with clams from Dungeness West being heavier than clams at any other site, followed by Santa Cruz Island, both intertidal sites, and lastly Catalina Island (Fig. 4A). Dungeness West, Santa Cruz Island, and San Quintin were not significantly different from each other based on their average valve lengths, but were significantly larger than any other sites followed by Bodega Bay. Morro Bay and Catalina Island showed no significant difference in average valve length, but were significantly smaller in comparison to all other sites (Fig. 4B). 


\begin{tabular}{|c|c|c|c|c|c|c|c|}
\hline & צ & 오․ & in & $\frac{10}{0}$ & $\underset{N}{N}$ & $\stackrel{+}{0}$ & $\frac{\pi}{2}$ \\
\hline 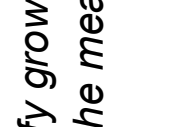 & $\stackrel{\underline{E}}{=}$ & $\begin{array}{l}\stackrel{9}{-} \\
\dot{\square}\end{array}$ & $\begin{array}{l}m \\
\stackrel{m}{m} \\
\end{array}$ & $\begin{array}{l}\stackrel{O}{\mathfrak{N}} \\
\stackrel{N}{\sim}\end{array}$ & $\begin{array}{l}\hat{\infty} \\
\infty \\
m\end{array}$ & $\stackrel{0}{\tilde{O}}$ & $\frac{\mathbb{\sigma}}{\mathrm{I}}$ \\
\hline 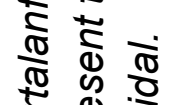 & 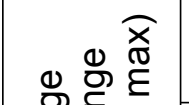 & 움 & $\stackrel{\sim}{\sim}$ & $\underset{+}{\mathscr{O}}$ & $\stackrel{Q}{N}$ & ๑ి & $\frac{\pi}{\underline{c}}$ \\
\hline बे & ४ & 10 & $\nabla$ & $\lambda$ & $\infty$ & の & $\frac{\sigma}{I}$ \\
\hline 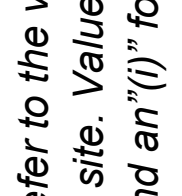 & 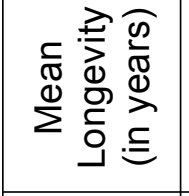 & $\mid \begin{array}{l}0 \\
+1 \\
1 \\
\infty\end{array}$ & $\begin{array}{l}r \\
+1 \\
20\end{array}$ & 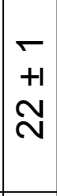 & $\begin{array}{l}+ \\
+1 \\
1 \\
0\end{array}$ & $\begin{array}{l}0 \\
+1 \\
1 \\
10\end{array}$ & $\frac{\pi}{\Omega}$ \\
\hline 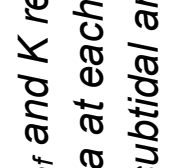 & 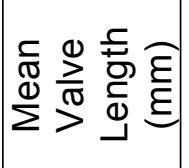 & $\begin{array}{l}r \\
+1 \\
\sim \\
m \\
\sigma\end{array}$ & $\begin{array}{l}0 \\
+1 \\
\circ \\
\stackrel{1}{\sim}\end{array}$ & $\begin{array}{l}m \\
+1 \\
0 \\
\frac{0}{\sigma}\end{array}$ & $\begin{array}{l}m \\
+1 \\
\hat{m} \\
-\end{array}$ & $\begin{array}{l}0 \\
+1 \\
5 \\
\frac{0}{2}\end{array}$ & $\begin{array}{l}m \\
+1 \\
\hat{m} \\
m\end{array}$ \\
\hline 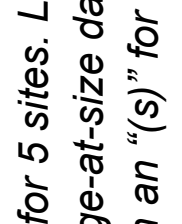 & 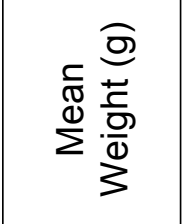 & $\begin{array}{l}\underset{N}{N} \\
+1 \\
+ \\
\stackrel{0}{\leftarrow}\end{array}$ & $\begin{array}{l}m \\
\infty \\
+1 \\
\widetilde{N} \\
\tilde{\infty}\end{array}$ & 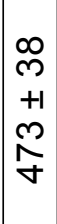 & $\left|\begin{array}{c}0 \\
1 \\
+1 \\
+1 \\
\infty \\
\infty\end{array}\right|$ & $\left|\begin{array}{l}\bar{m} \\
+1 \\
\hat{\rho} \\
m\end{array}\right|$ & $\stackrel{\sigma}{\beth}$ \\
\hline$\frac{0}{0} \stackrel{0}{\frac{1}{2}}$ & $\subset$ & 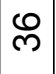 & ○ & 유 & $\hat{m}$ & $\stackrel{\sim}{m}$ & ஓ \\
\hline 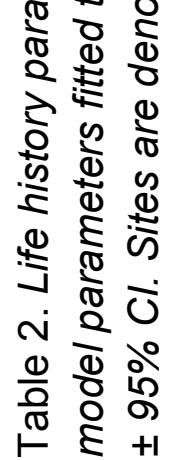 & 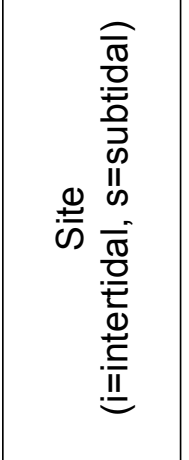 & 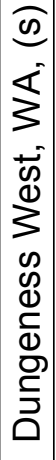 & 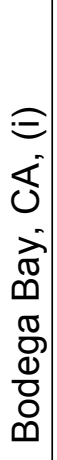 & 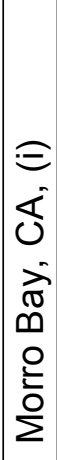 & 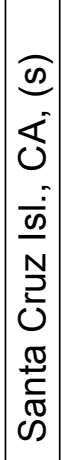 & 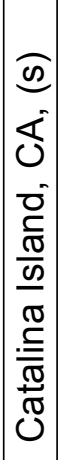 & 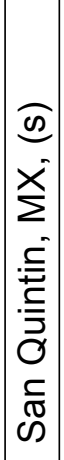 \\
\hline
\end{tabular}



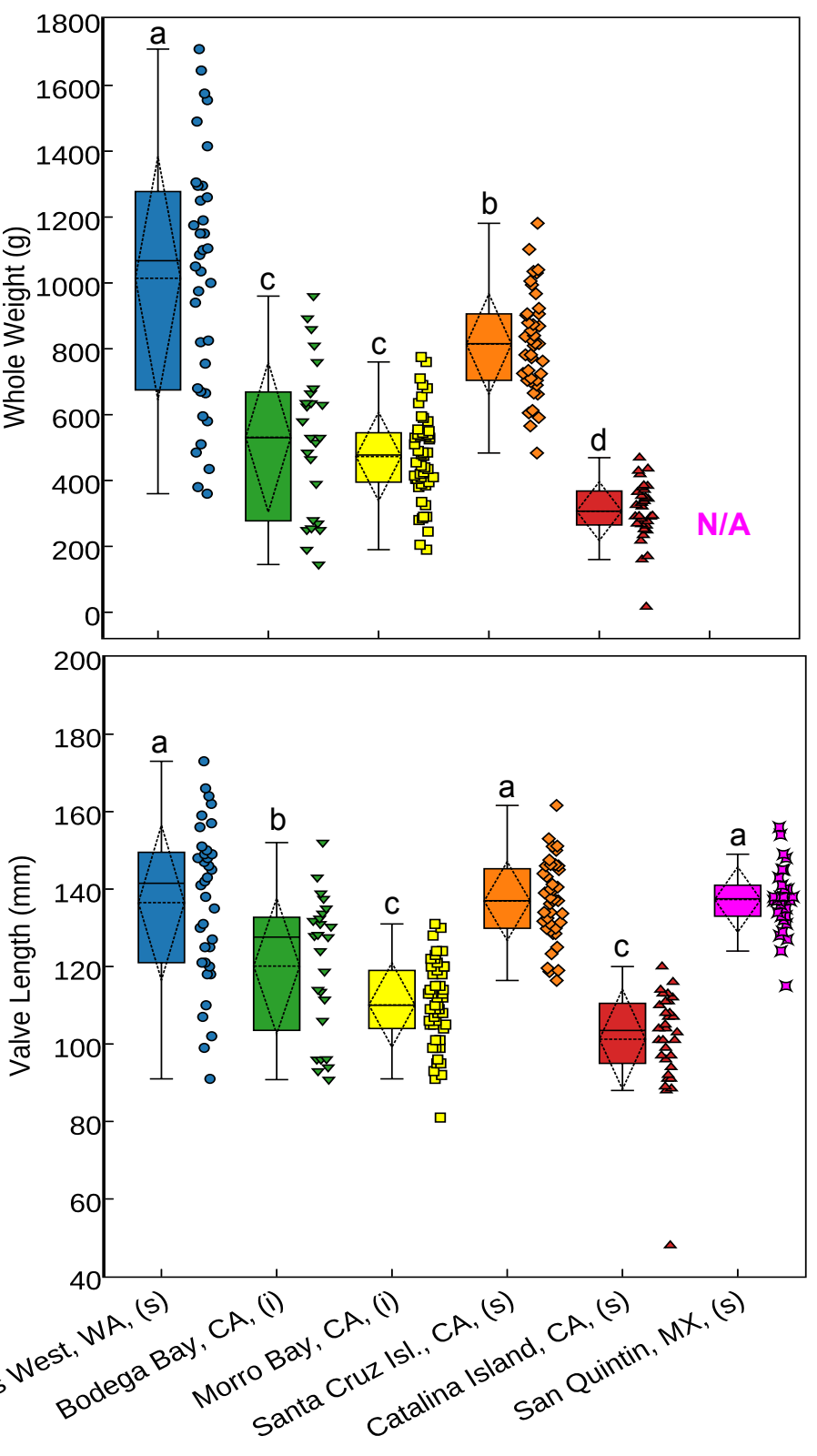

Figure 4. Geoduck whole weight (top graph) and valve length (bottom graph) comparisons by site. Boxes represent quartiles. The dots next to the boxes are the raw data points for each site. The horizontal dotted line in each box indicates site mean value. The solid horizontal line indicates the median of the site data. No whole weight data were available for San Quintin, Mexico. The Tukey HSD post-hoc test results are shown as lower case letters above boxes. All means are significantly different if they are not sharing any letters. Each site is denoted with an "(s)" for subtidal and an "(i)" for intertidal. 
Valve length was a significant predictor of whole weight across all sampling locations (Fig. 5) and length-weight relationships were well described by a non-linear power function $\left(Y=a^{*} X^{b}\right.$; Table 3). Interestingly, the powerscaling parameter $b$ increased with increasing latitude up to Bodega Bay and decreased slightly at Dungeness West (Table 3). 

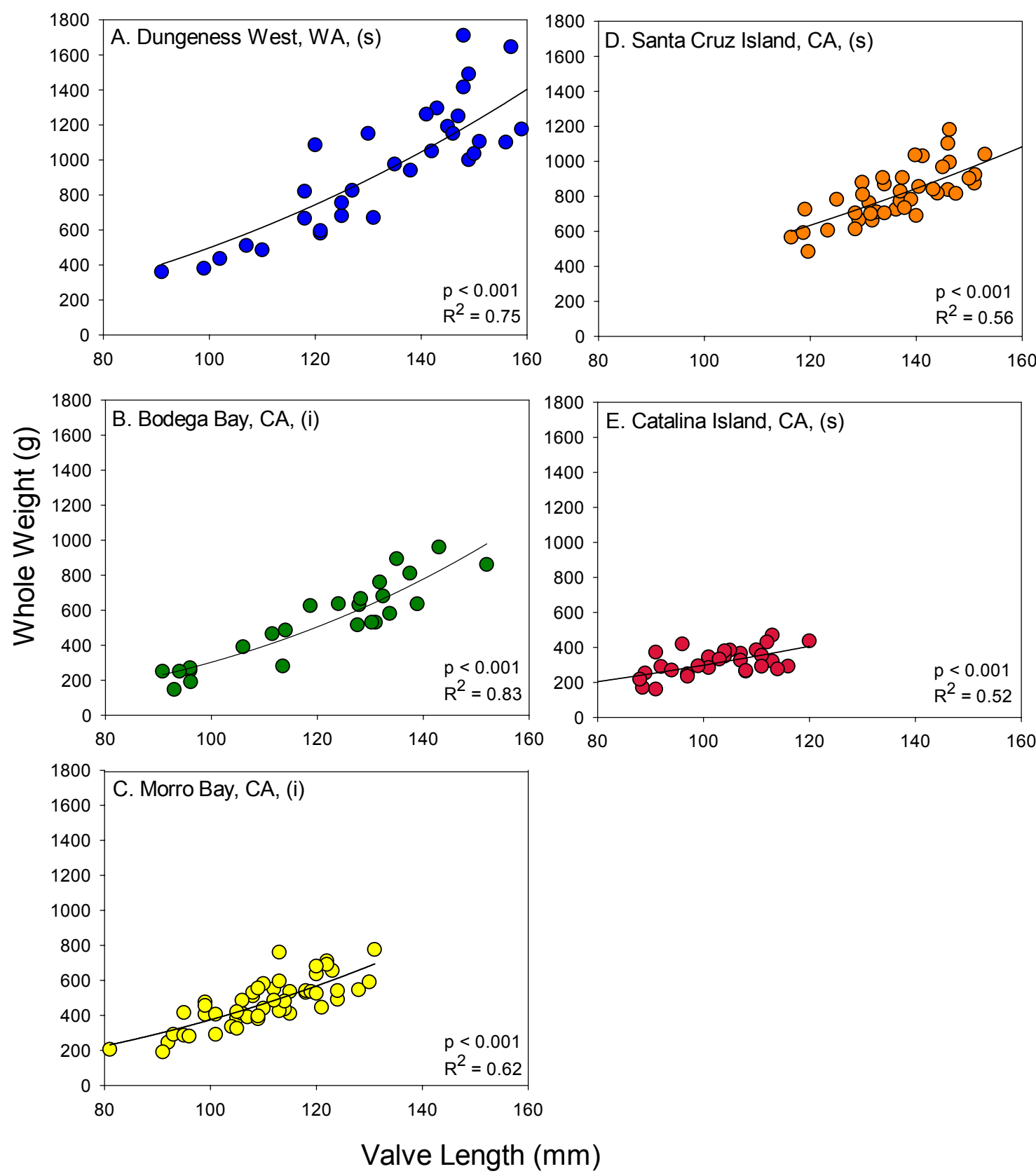

Figure 5. Length-weight relationships for geoducks from 5 study locations. A) Dungeness West, WA; B) Bodega Bay, CA; C) Morro Bay, CA; D) Santa Cruz Island, CA; E) Catalina Island, CA. Each site is denoted with an "(s)" for subtidal and an "(i)" for intertidal. 


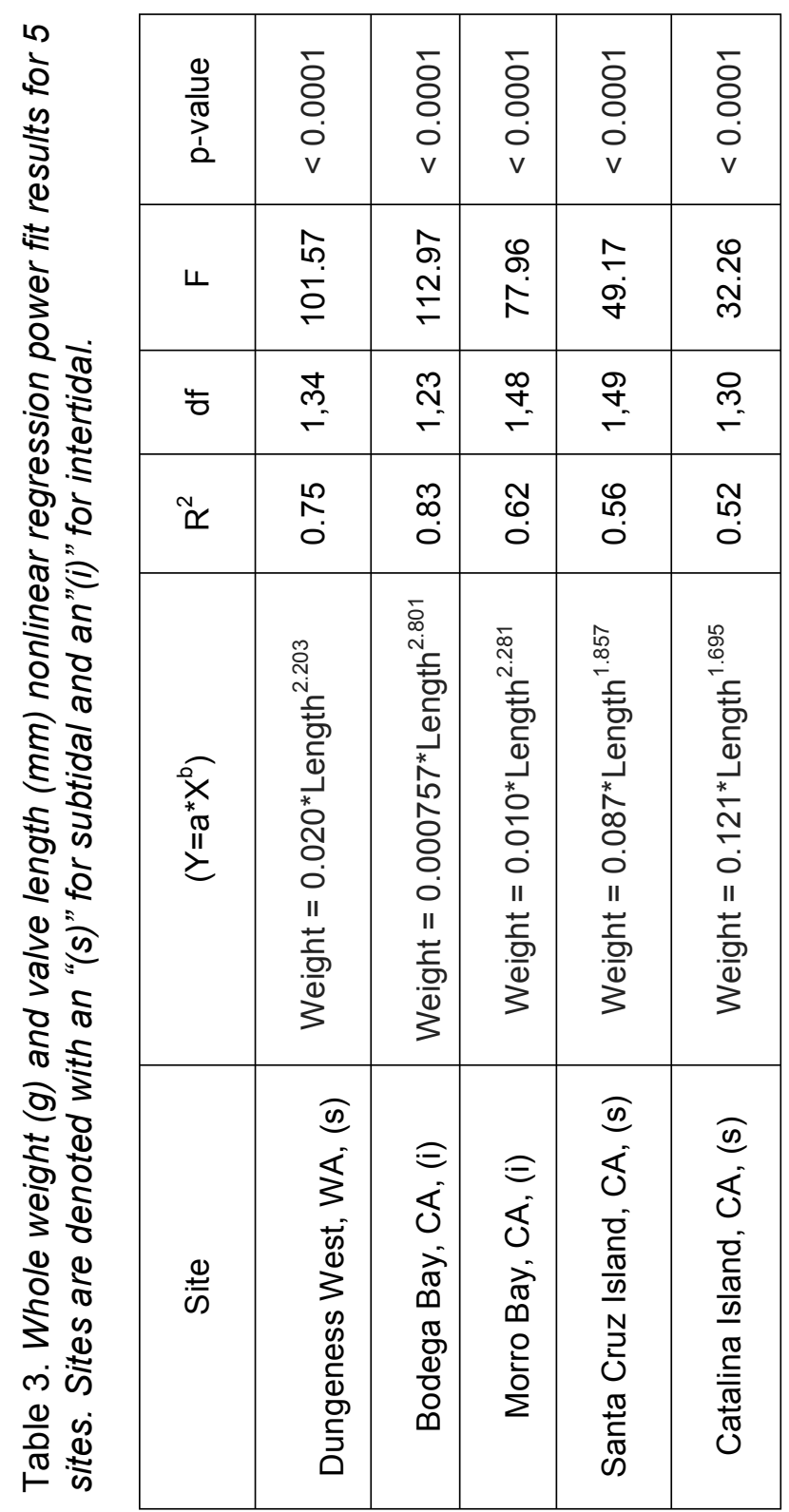

Clams showed significant spatial differentiation in the Fulton's $\mathrm{K}$ body condition factor (ANOVA, $\mathrm{F}_{4,179}=14.69, \mathrm{p}<.0001$; Fig. 6). Tukey HSD post-hoc 
test results revealed that clams from Dungeness West and Morro Bay were in significantly better condition than clams from other locations. Bodega Bay, Santa Cruz Island, and Catalina Island showed no significant differences in body condition according to post-hoc results. These results indicate that clams were heavier for a given length at those locations where the condition factor was higher.

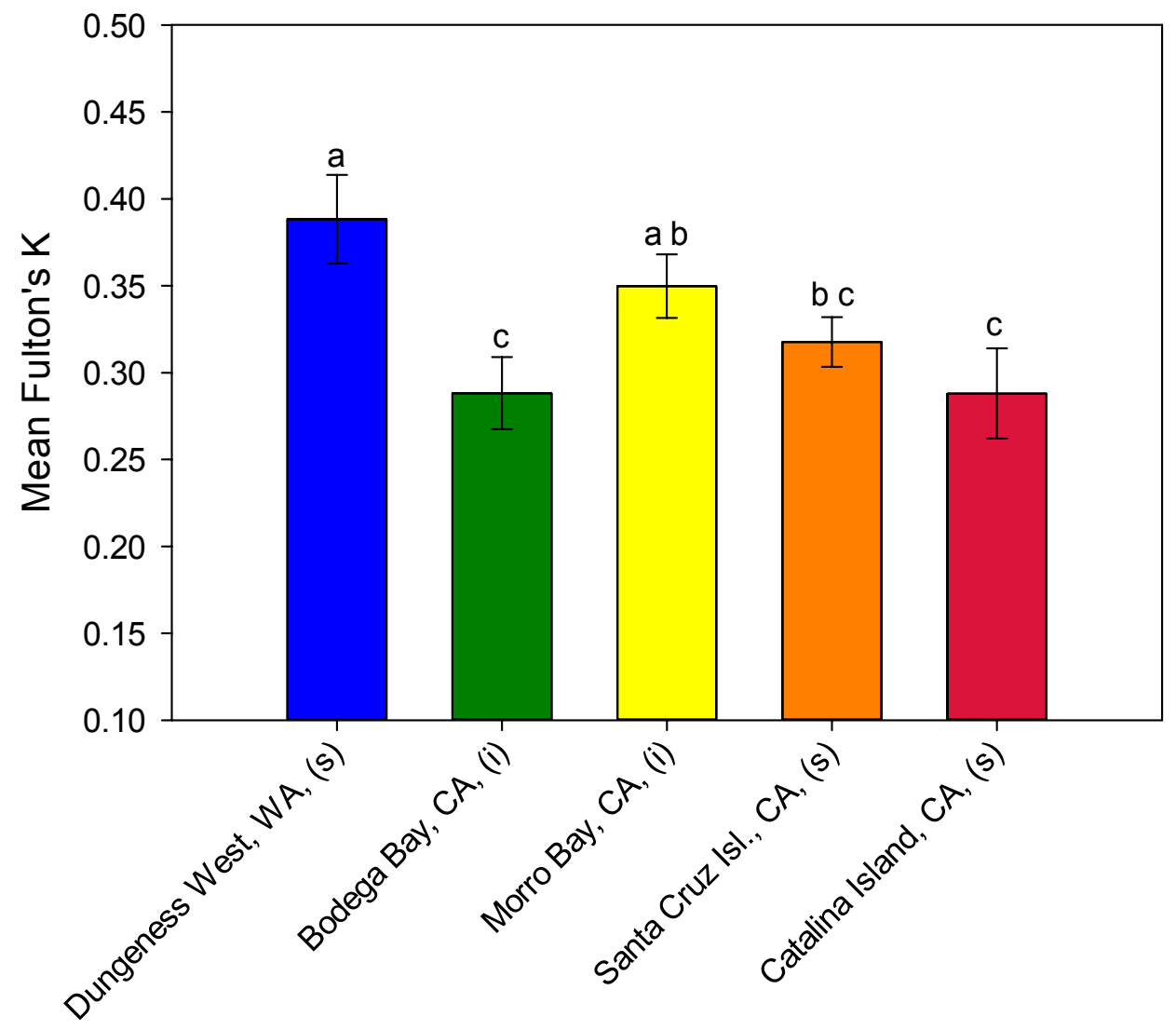

Figure 6. Fulton's body condition factor $(\mathrm{K})$ averages by site. Error bars represent $\pm 95 \% \mathrm{Cl}$. The Tukey HSD post-hoc test results are shown as lower case letters above bars. Means not sharing the same letters are significantly different. Each site is denoted with an "(s)" for subtidal and an "(i)" for intertidal. 


\section{Age, Growth, and Environmental Correlates}

Age-frequency distributions of geoducks differed significantly (ANOVA, $\left.F_{4,172}=32.96, p<.0001\right)$ among sampling locations (Fig. 7; Table 2). Clams from Dungeness West exhibited the largest age span of all five sites (5-104 years), whereas Bodega Bay (4-20 years) and Morro Bay (7-46 years) showed the smallest range of ages of all sites, with frequent occurrences of individuals representing younger age classes. Santa Cruz Island (8-76 years) and Catalina Island (9-65 years) fell between Dungeness West and the two intertidal bay sites with a larger range of age classes represented, but less representation of the older age classes compared to Dungeness West. 


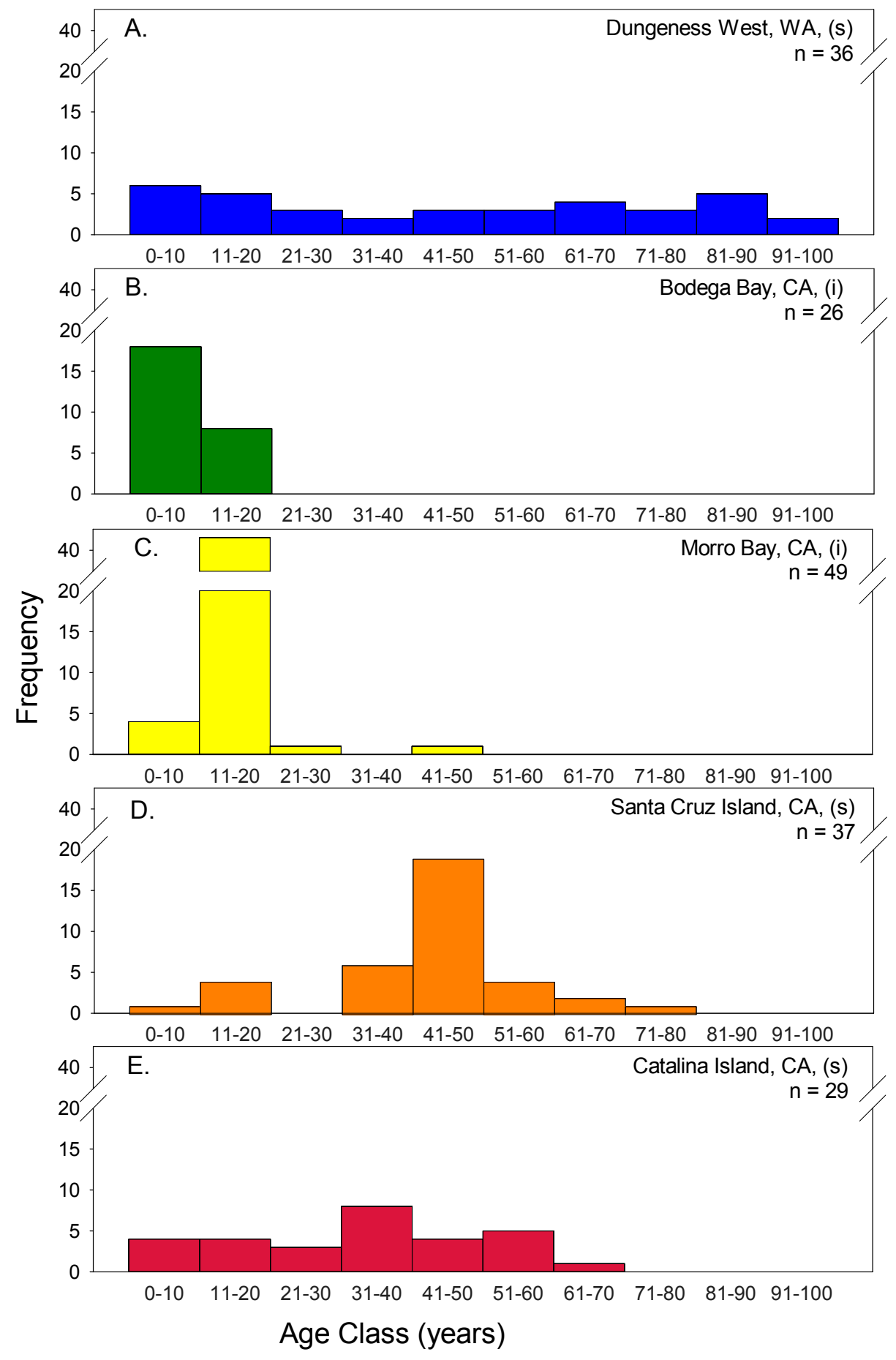

Figure 7. Age-frequency distributions of geoduck clams for 5 of the sampling locations in California and Washington. Note: age classes are binned in 10-year increments. Each site is denoted with an "(s)" for subtidal and an "(i)" for intertidal. 
Life expectancy, or longevity (mean of top quartile of clam ages) differed significantly among sampling locations (ANOVA, $F_{4,40}=118.58, p<.0001$; Fig. 8). The trend was revealed via the Tukey HSD post-hoc indicating that life expectancy is greatest at Dungeness West (subtidal), followed by both subtidal island sites, and lastly the two intertidal bay locations.

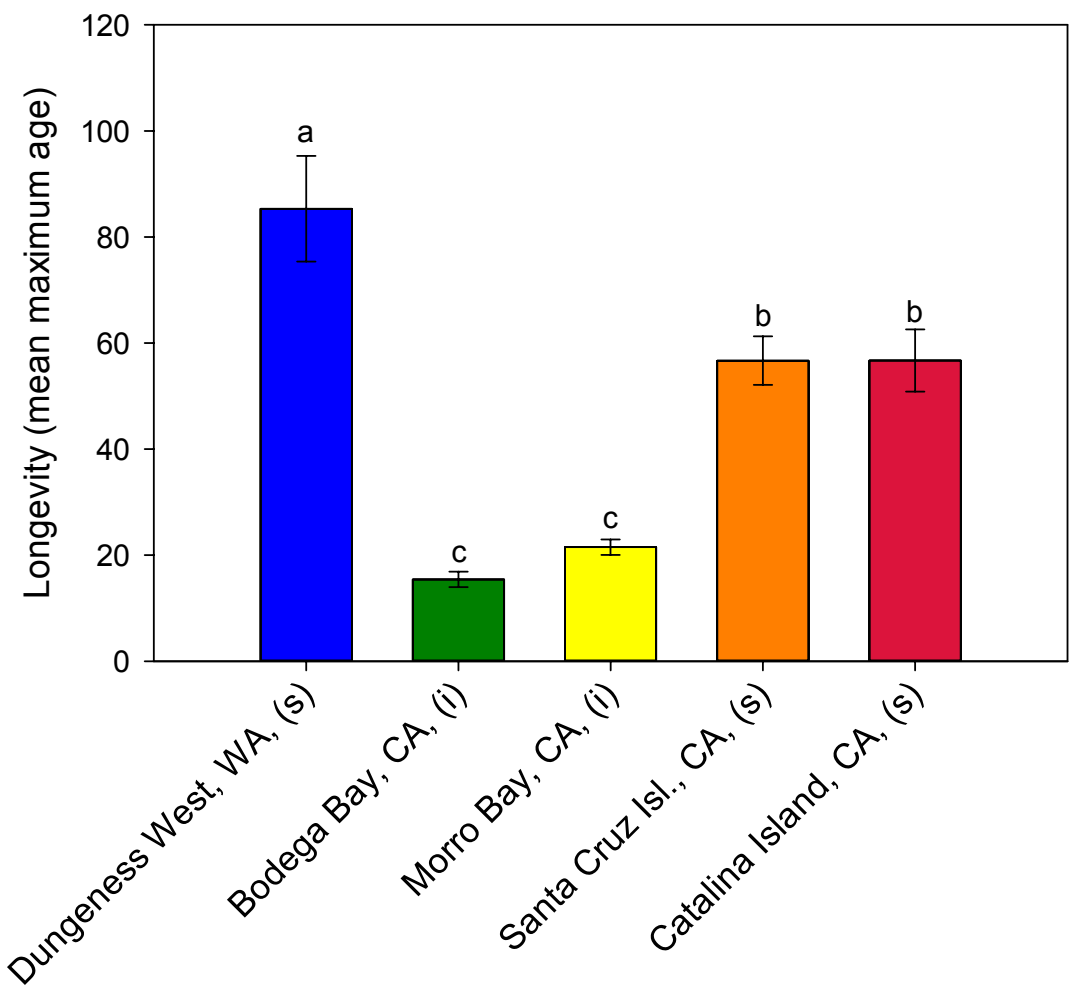

Figure 8. Longevity means for 5 sites (mean of top quartile of clam ages, $\pm 95 \% \mathrm{Cl}$ ). The Tukey HSD post-hoc test results are shown as lower case letters above bars. Means with same letters are not significantly different. Each site is denoted with an "(s)" for subtidal and an "(i)" for intertidal.

Comparisons of longevity to the average sea surface temperature (SST in ${ }^{\circ} \mathrm{C}$ ) and chlorophyll a ( $\mathrm{Chl} \mathrm{a} \mathrm{in} \mathrm{mg}^{*} \mathrm{~m}^{-3}$ ) levels from 2002 to 2012 revealed no 
significant correlations across the sampling locations (SST: $r=2.0 \times 10^{-6}, p=$ 0.9974; Chl a: $r=0.37, p=0.5438)$.

Geoducks exhibited significant geographic variability in lifetime growth curves among the sampling locations (Fig. 9). Dungeness West, Bodega Bay, and Santa Cruz Island had the highest asymptotic length parameter value ( $\mathrm{L}_{\text {inf; }}$; Fig. 9A, B, D) after fitting the VBGM to the length-at-age data, whereas Morro Bay and Catalina Island had the lowest values of $L_{\text {inf }}($ Fig. 9B, E). Bodega Bay exhibited the highest growth rate coefficient $(K)$ at 0.25 , followed by Catalina Island $(K=0.24)$, Santa Cruz Island $(K=0.22)$, Dungeness West $(K=0.20)$, and Morro Bay $(K=0.15)$. Significant differences in growth curves can be visualized by examining the bivariate plot of $95 \%$ confidence intervals around the growth parameters of $\mathrm{L}_{\text {inf }}$ and $K$ (Fig. 10). Clams from Dungeness West, Bodega Bay and Santa Cruz Island have similar growth patterns, while lifetime growth curves are significantly different at Morro Bay and Catalina Island, primarily driven by a lower $\mathrm{L}_{\text {inf. }}$ 

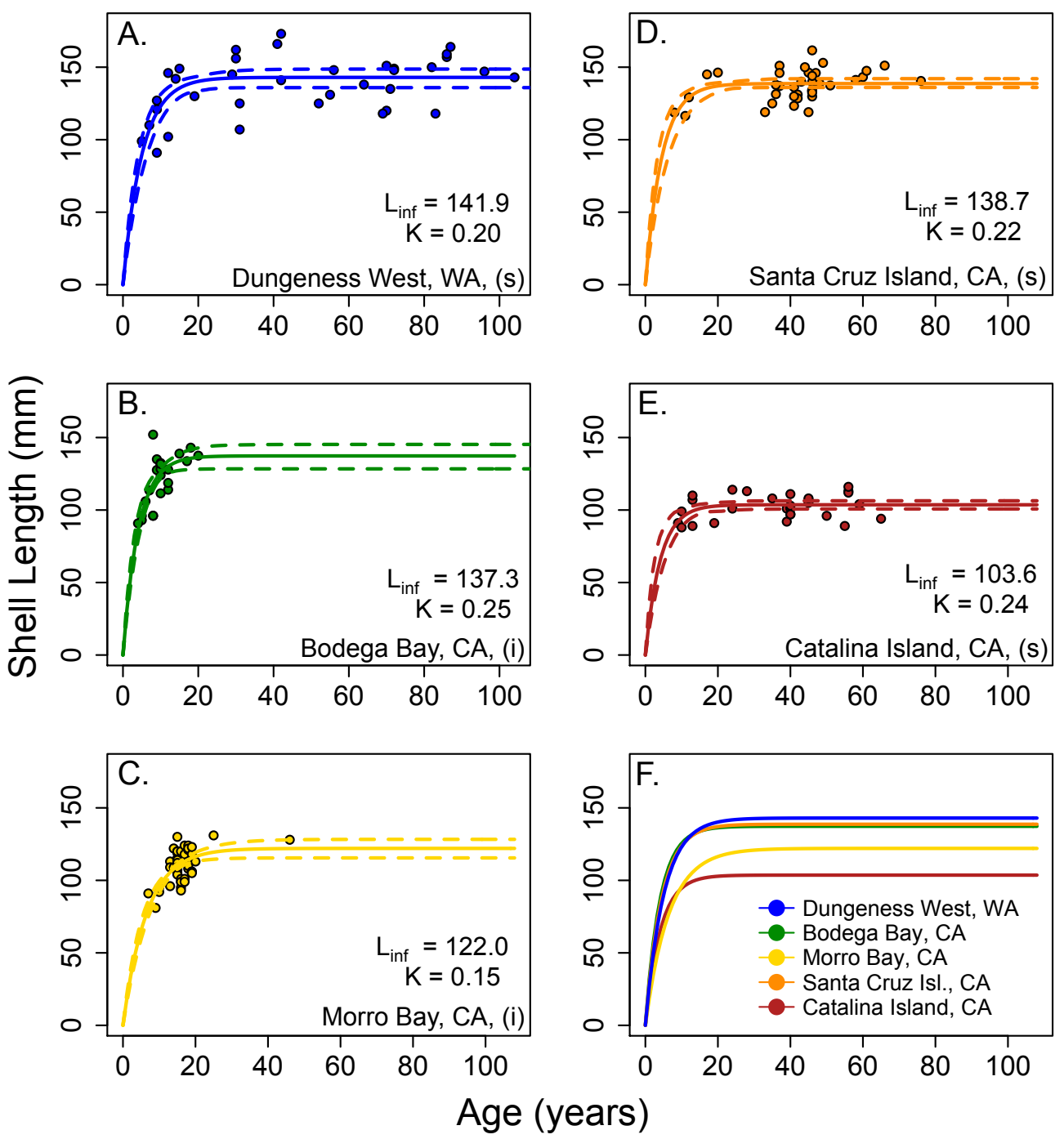

Figure 9. Geographic variation in lifetime growth curves of geoducks from 5 study locations (A-E). Each site is denoted with an "(s)" for subtidal and an "(i)" for intertidal. Von Bertalanffy growth model (VBGM) were fit to length-at-age data for each site (solid line) and $\pm 95 \% \mathrm{Cl}$ (dashed lines). VBGM curves for each site superimposed $(F)$. 


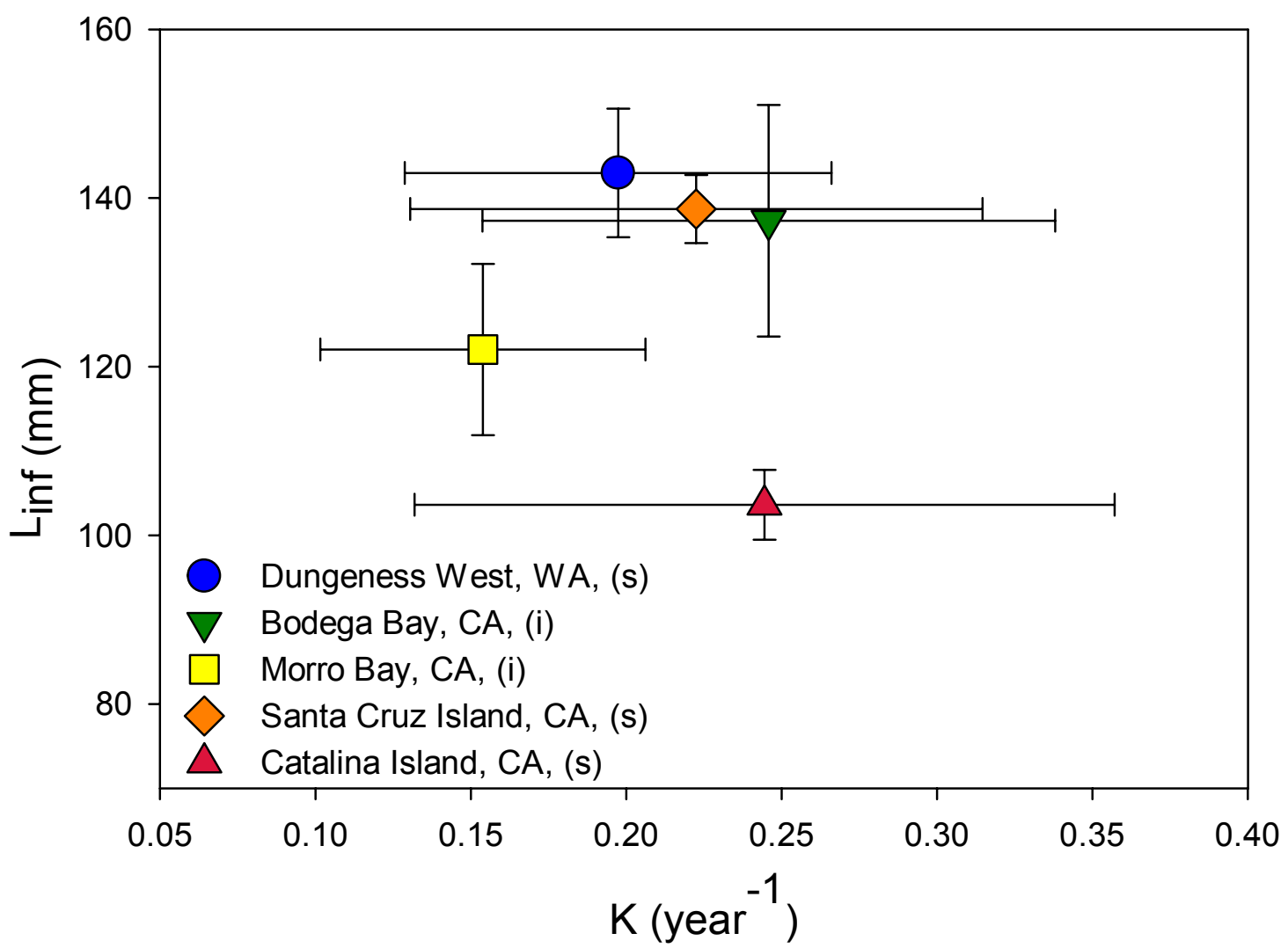

Figure 10. Von Bertalanffy growth parameters for each study location. Error bars represent $\pm 95 \% \mathrm{Cl}$. Each site is denoted with an "(s)" for subtidal and an "(i)" for intertidal.

VBGM parameters for the five sites were compared to the 10-year (20022012) mean of SST $\left({ }^{\circ} \mathrm{C}\right)$ and $\mathrm{Chl} a\left(\mathrm{mg}^{*} \mathrm{~m}^{-3}\right)$ levels (Fig. 11). Neither $\mathrm{L}_{\text {inf, }}$, nor $K$ showed any significant associations with either environmental variable at any of the five sites. However, there were negative trends between $\mathrm{L}_{\text {inf }}$ and SST $\left(r^{2}=0.54, p=0.16\right.$; Fig. $\left.11 \mathrm{~A}\right)$ and positive trends between $\mathrm{L}_{\text {inf }}$ with $\mathrm{Chl} a$ $\left(r^{2}=0.41, p=0.25\right.$; Fig. 11B $)$, indicating that clams reached larger sizes at locations that were cooler and more productive. Despite low sample sizes (only 5 populations) and thus low statistical power, $54 \%$ of the variation in asymptotic 
size among locations could be explained by average temperature and $41 \%$ of the variation could be explained by $\mathrm{Chl}$ a or productivity. The growth or curvature parameter $K$ exhibited the opposite pattern to $\mathrm{L}_{\text {inf }}$, but with much weaker trends (Fig. 11).
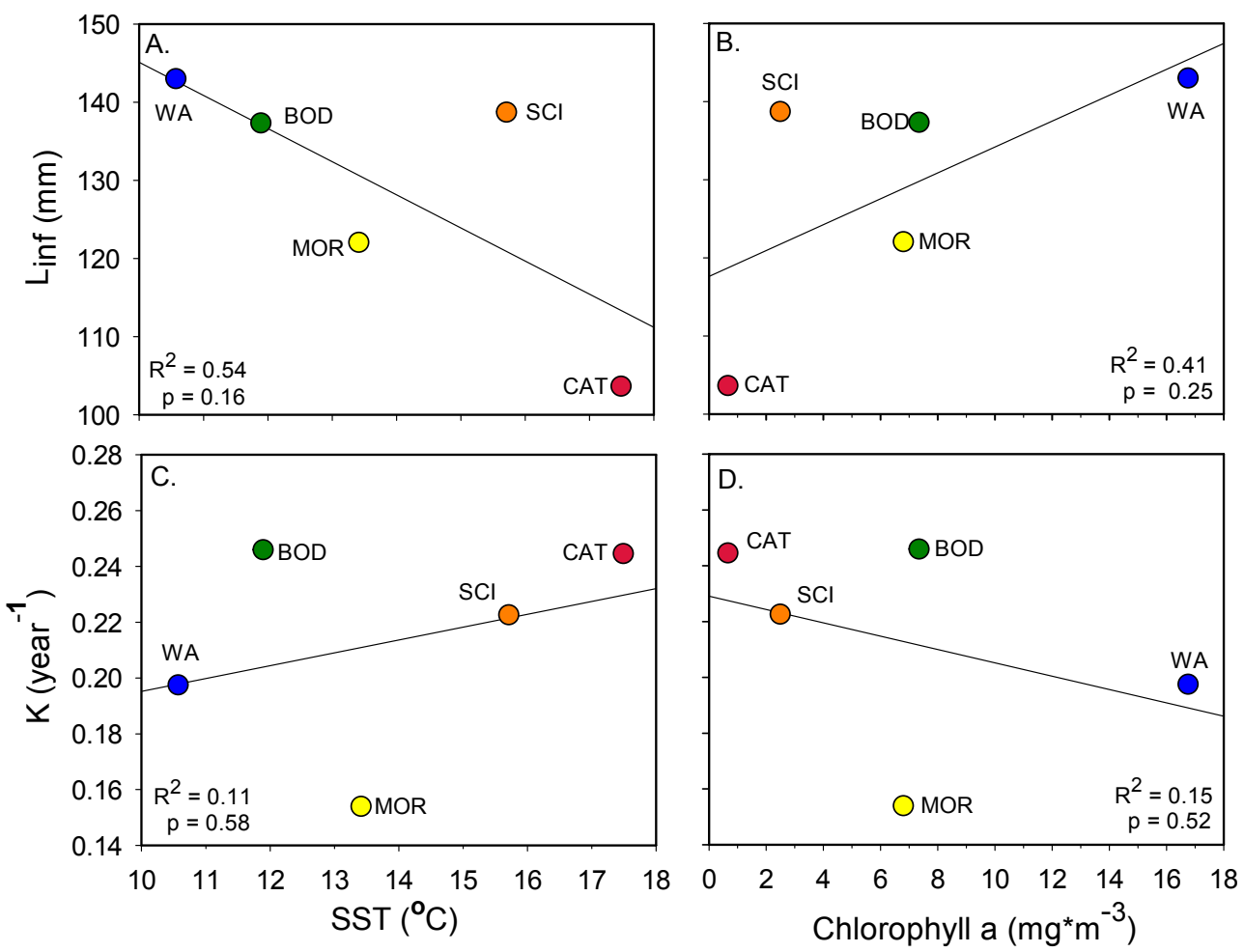

Figure 11. Relationships between geoduck life history variables and regional environmental conditions (A-D). Von Bertalanffy growth parameters for 5 sites compared to ten-year averages (2002-2012) of sea surface temperatures $\left(\mathrm{SST},{ }^{\circ} \mathrm{C}\right)$ and chlorophyll a $\left(\mathrm{Chl} \mathrm{a}, \mathrm{mg}^{*} \mathrm{~m}^{-3}\right)$ levels. WA = Dungeness West, WA, BOD= Bodega Bay, CA, MOR= Morro Bay, $\mathrm{CA}, \mathrm{SCl}=$ Santa Cruz Island, CA, CAT= Catalina Island, CA.

\section{Spatial Variability in Geoduck Morphology}

Geoducks exhibited highly significant spatial variability in shell morphology among the six sampling locations (Fig. 12). The CVA results indicated that $73 \%$ 
of the variation in shell morphology was explained by the first two canonical variate (CV) axes (Table 4; Fig. 12). CV1 explained $52.3 \%$ of the variation and was characterized by changes in shell shape along the dorsoventral axis (from the umbo to the valve opening). For example, Catalina Island shells were more dorsoventrally compressed (positive CV1 value), whereas Dungeness West clams were more dorsoventrally expanded (negative CV1 value) in comparison to shells from all other locations. CV2 explained $20.9 \%$ of the variation in shell morphology as a function of geographic location and was characterized by changes in shell shape along the anteroposterior axis (from the area where a shell digs into the sand to the area where the siphon is located). While Bodega Bay, Morro Bay, Santa Cruz Island, and San Quintin shells were similar in shape along the dorsoventral axis (CV1), shells from these locations showed much more shape variation along the anteroposterior axis (CV2). The two intertidal sites, Bodega Bay and Morro Bay, exhibited a widening of the anterior end of the shells, whereas subtidal sites like Santa Cruz Island and San Quintin were compressed at the anterior end of the shells.

Mahalanobis distances, the test statistic used to determine significant differences in multivariate measures of shape among sampling locations, indicated highly significant $(p<0.0001)$ differences among all groups (Table 5$)$. Bodega Bay and Morro Bay exhibited the least amount of difference in distance to the grand average Procrustes distances, indicating that shells from these 
locations were representative of the average geoduck shell shape among sampling locations.
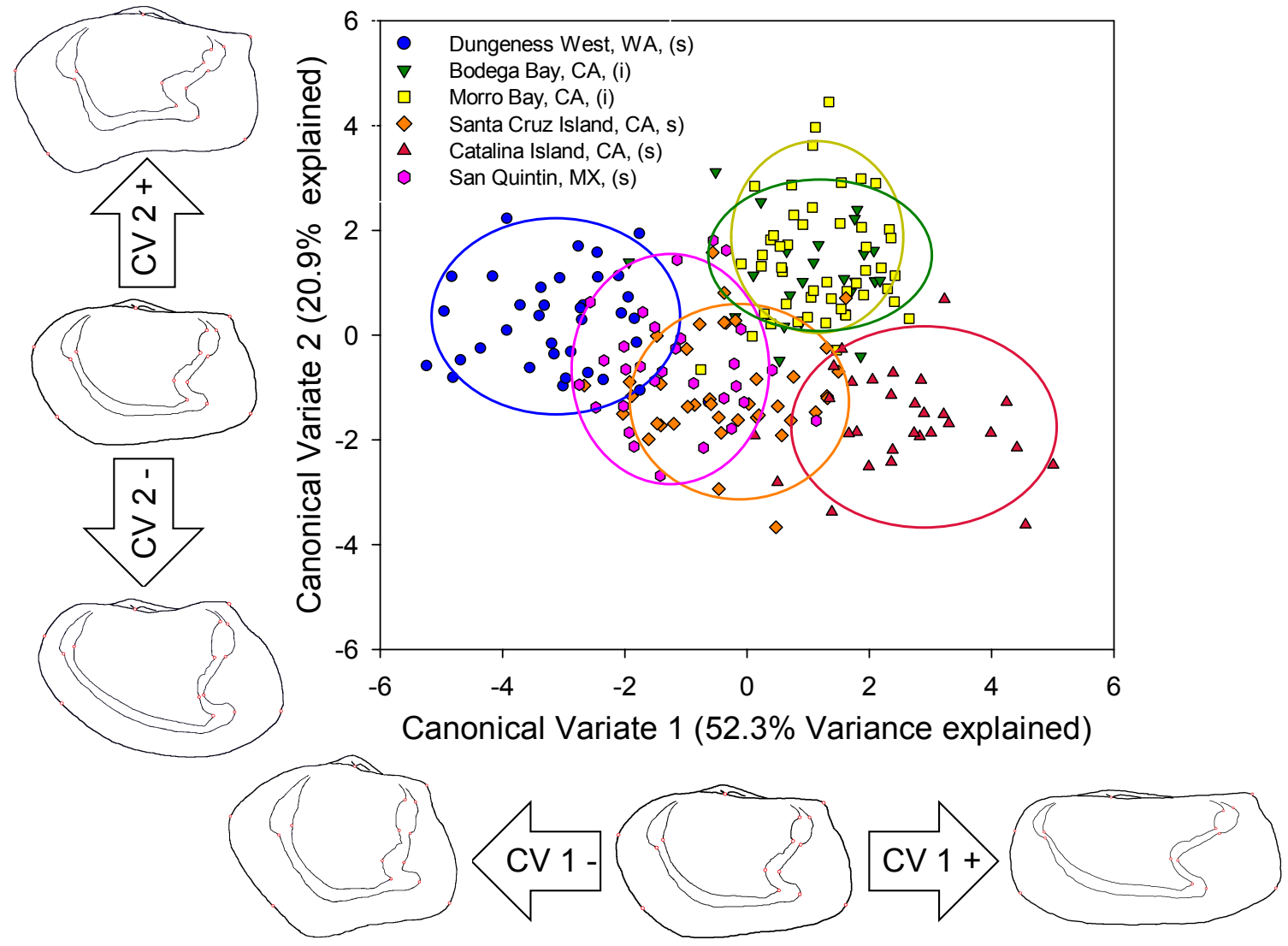

Figure 12. Each point represents the shape of a clamshell. Sites are denoted by colors. Intertidal and subtidal sites are marked by "(i)" and "(s)" respectively. The zero point of each axis denotes the grand average of all sites. Canonical Variate 1 (CV1) axis explains $52.3 \%$ of the variation in shell shape and represents the degree of dorso-ventral compression of a shell. Canonical Variate 2 (CV2) explains $20.9 \%$ of the variation in shell shape and represents the degree of antero-posterior variation in a shell. The ellipses represent the $90 \%$ confidence intervals for each site. 
Table 4. Shape variation among groups, scaled by the inverse of the within-group variation.

\begin{tabular}{|c|c|c|c|}
\hline Canonical Variate & Eigenvalues & \% Variance & Cumulative \% \\
\hline 1 & 3.32759414 & 52.298 & 52.298 \\
\hline 2 & 1.33109200 & 20.920 & 73.218 \\
\hline 3 & 1.01926497 & 16.019 & 89.238 \\
\hline 4 & 0.40212419 & 6.320 & 95.558 \\
\hline 5 & 0.28264376 & 4.442 & 100.000 \\
\hline
\end{tabular}

Table 5. Mahalanobis distances measured in Procrustes distance among groups ( $p$-values $<.0001$ from 10,000 rounds permutation tests). Each site is denoted an "(s)" for subtidal and an "(i)" for intertidal.

\begin{tabular}{|l|l|l|l|l|l|}
\hline \multicolumn{1}{|c|}{ Site } & $\begin{array}{l}\text { Dungeness } \\
\text { West, WA }\end{array}$ & $\begin{array}{l}\text { Bodega } \\
\text { Bay, CA }\end{array}$ & $\begin{array}{l}\text { Morro } \\
\text { Bay, CA }\end{array}$ & $\begin{array}{l}\text { Santa Cruz } \\
\text { Isl., CA }\end{array}$ & $\begin{array}{l}\text { Catalina } \\
\text { Isl., CA }\end{array}$ \\
\hline Dungeness West, WA, (s) & & & & & \\
\hline Bodega Bay, CA, (i) & 4.5807 & & & & \\
\hline Morro Bay, CA, (i) & 4.7294 & 2.0451 & & & \\
\hline Santa Cruz Isl., CA, (s) & 3.6557 & 3.1335 & 3.1539 & & \\
\hline Catalina Isl., CA, (s) & 5.9679 & 3.6708 & 3.6750 & 3.6486 & \\
\hline San Quintin, MX, (s) & 3.8456 & 3.9764 & 3.6663 & 2.6463 & 4.8505 \\
\hline
\end{tabular}

Significant differences in shell shape among locations were reflected in the site-by-site Procrustes distances, measuring the absolute amount of shape difference (Table 6). Bodega Bay and Morro Bay, the two intertidal sites, were more similar to each other in shell shape than any of the other subtidal locations with $90 \%$ of the shape values on the positive CV2 axis. This result indicates that the intertidal clams at these two sites show a widening in the anterior region close the ventral region (or valve opening) as compared to the subtidal sites. The subtidal locations were significantly different from the intertidal sites based 
on shell shape, with differences in shape primarily occurring on the dorsoventral axis of the shell (CV1 axis).

Table 6. Procrustes distances among groups ( $p$-value $<.0001$ after 10,000 round permutation test for all sites, with exception of Morro Bay and Bodega Bay, $p$-value = 0.0197). Each site is denoted an "(s)" for subtidal and an "(i)" for intertidal.

\begin{tabular}{|l|l|l|l|l|l|}
\hline \multicolumn{1}{|c|}{ Site } & $\begin{array}{l}\text { Dungeness } \\
\text { West, WA }\end{array}$ & $\begin{array}{l}\text { Bodega } \\
\text { Bay, CA }\end{array}$ & $\begin{array}{l}\text { Morro } \\
\text { Bay, CA }\end{array}$ & $\begin{array}{l}\text { Santa } \\
\text { Cruz Isl., } \\
\text { CA }\end{array}$ & $\begin{array}{l}\text { Catalina } \\
\text { Island, CA }\end{array}$ \\
\hline Dungeness West, WA, (s) & & & & & \\
\hline Bodega Bay, CA, (i) & 0.0414 & & & & \\
\hline Morro Bay, CA, (i) & 0.0702 & 0.0338 & & & \\
\hline Santa Cruz Isl., CA, (s) & 0.0721 & 0.0375 & 0.0538 & & \\
\hline Catalina Isl., CA, (s) & 0.0849 & 0.0414 & 0.0564 & 0.0458 & \\
\hline San Quintin, MX, (s) & 0.0495 & 0.0548 & 0.0572 & 0.0496 & 0.0680 \\
\hline
\end{tabular}

The log centroid size of clams (i.e., a proxy for clamshell size) did not significantly predict shape at any site (Fig. 13) except for Catalina Island $\left(r^{2}=0.23\right.$, $p=0.02$; Fig. 13E). Shell shape systematically changed with age only at Catalina Island where there was a trend for shells to be more dorsoventrally compressed as well as slightly more narrow at the anterior end as clams got older $\left(r^{2}=0.11\right.$, $p=0.002$; Fig. 14E). 

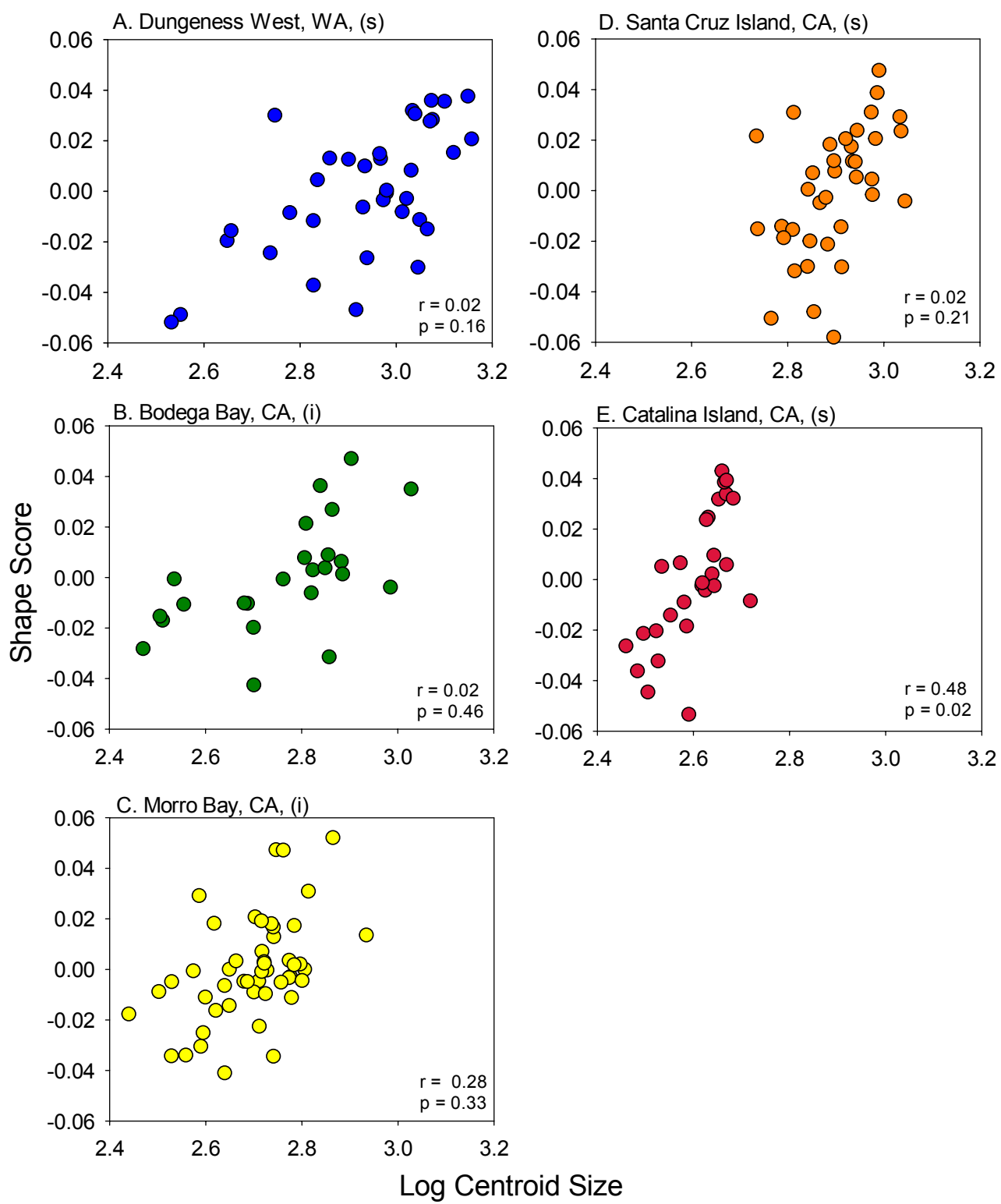

Figure 13. (A-E) Log Centroid Size versus Shape Score. All sites with the exception of Catalina Island $(p=0.02, r=0.48)$ show that Centroid Size is not a predictor of shape. Each site is denoted with an "(s)" for subtidal and an "(i)" for intertidal. 

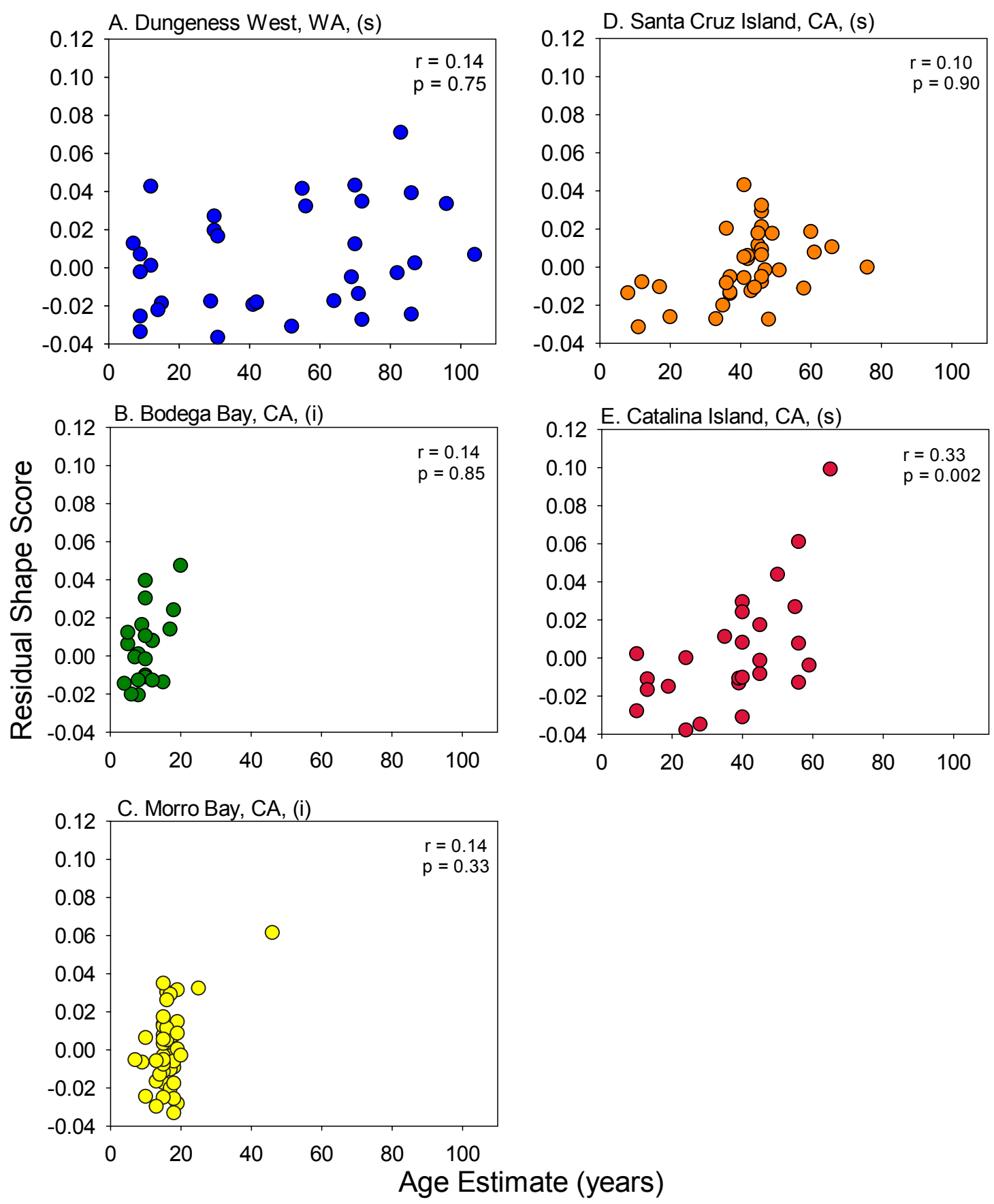

Figure 14. (A-E) Residual shape scores from Fig. 13 (shape versus centroid size) were used to evaluate age as a predictor of shape irrespective of any possible allometric (size) effects inherent in shape. Each site is denoted with an "(s)" for subtidal and an "(i)" for intertidal. 


\section{Discussion}

This study is the first to investigate geoduck population demography and dynamics in California. Comparisons of life history and morphological traits revealed significant differences in length-weight relationships, body condition, longevity, lifetime growth parameters, and shell shape across the sites sampled. Size structure followed a latitudinal gradient with clams getting larger in northern latitudes, which coincided with larger asymptotic lengths reached. Growth was positively correlated with chlorophyll a $(\mathrm{Chl} a)$ and negatively correlated with sea surface temperature (SST), indicating that productivity could be responsible for these observations. Additionally, subtidal clams, irrespective of latitude, were characterized by an age distribution reflecting older individuals compared to the age structure of intertidal clams, potentially reflecting a depth refuge from harvesting. Valve shape analyses did not conform to any latitudinal pattern. However, intertidal sites were similar in shape featuring an anteroposterior expansion of valves, whereas subtidal sites were mostly dorsoventrally compressed.

\section{Geographic Variation in Size Structure and Condition}

Geoducks followed a latitudinal gradient in length, weight, and condition, with heavier and larger clams occurring in the northern latitudes. One possible explanation for this positive latitude versus size relationship is Bergmann's rule (Bergmann 1847), which relates this type of size increase in endotherms to a 
heat conservation mechanism: the larger the animal, the better it can conserve heat in the colder northern latitudes. There is evidence that Bergmann's rule applies to not only endotherms but ectotherms as well. Ray (1960) found that 13 out of 17 poikilotherms followed Bergmann's rule. However, there is controversy surrounding the applicability of Bergmann's rule to ectotherms. For example, studies have shown that the pattern of increasing size as a function of latitude is a phenotypic response to countergradient variation in environmental conditions, such as temperature and length of the growing season (e.g., the fruit fly Drosophila melanogaster, Levins 1968; the marine gastropod Bembicium vittatum, Parsons 1997). Similar to $P$. generosa, Caselle et al. (2011) reported that California sheephead attained larger sizes at higher latitudes that were characterized by colder temperatures, and also fewer competitors. Heilmayer et al. (2004) showed a significant correlation between the growth efficiency in scallops and temperature, with elevated temperatures constraining growth. Frank (1975) found a strong latitudinal pattern of the black turban snail, Tegula funebralis, with snails in the northern latitudes living longer and growing more slowly, but ultimately attaining larger sizes than in the southern latitudes. Latitudinal differentiation favoring faster development rate and larger adult size was also found in a copepod collected over a broad latitudinal scale: Lonsdale and Levinton (1985) found significant latitudinal differentiation in the estuarine copepod Scottolana canadensis that persisted even when reared in common conditions. In contrast, Ruttenberg et al. (2005) showed that Stegastes beebii 
reached larger sizes and older ages in cooler locations at the Galapagos Islands, irrespective of latitude. Conover and Schultz (1995) used reciprocal transplant experiments with the Atlantic silverside (Menidia menidia) to test whether countergradient variation in growth and size (faster growth and larger individuals in cooler northern regions) was due to phenotypic plasticity in response to variable environmental conditions. Their results indicated a strong genetic basis for the observed differences in body form, growth, and condition across a broad latitudinal range off the east coast of North America. Transplanting of juvenile geoducks is a common practice in aquaculture facilities in the Pacific Northwest. Thus, reciprocal transplant experiments are a feasible option to address the potential genetic basis of the observed latitudinal size differences in geoducks in the future.

Every latitude features differences in SST and Chl a. Geoducks are filter feeders that inhabit habitats ranging from highly variable temperatures in the intertidal to less variable subtidal temperature regimes. Both SST and $\mathrm{Chl}$ a may influence geographic patterns in body condition and weight-length relationships in these clams. Chl a, a proxy for oceanographic productivity, shows a strong negative correlation with temperature. Due to this autocorrelation, it is difficult to separate whether temperature, productivity, or both may be driving the observed size variation in $P$. generosa. However, previous studies have shown that size is positively correlated with Chl a in mussels (Page and Hubbard 1987) and 
scallops (MacDonald and Thompson 1985), which lends support for this hypothesis in geoducks.

\section{Age, Growth, and Environmental Correlates}

There were striking differences in age frequency distributions among subtidal and intertidal locations. Geoduck populations in the intertidal sites exhibited a dramatic truncation in older age classes relative to the subtidal sites. Thus clams were younger at the intertidal sites and older at the subtidal sites. This pattern suggests a potential depth refuge for the clams at the subtidal sites, where they experience higher survivorship compared to the shallower intertidal areas. Possible explanations for differential survivorship include decreased abiotic stress, lower predation, disease, parasitism, and reduced fishing pressure in subtidal compared to intertidal locations. Predation is likely to be greater on the subtidal clams than the intertidal clams and thus predation pressure is unlikely to explain the observed age structure variation in $P$. generosa. Predators of juvenile and adult geoducks include the sea stars Pisaster brevispinnus and Pycnopodia helianthoides (Mauzey et al. 1968; Sloan and Robinson 1983), which are more common in subtidal locations. Jensen (1995) reported that crabs prey on geoducks in Puget Sound, Washington. Three of the crab species Jensen observed are also found at the intertidal sites in this study (Bodega Bay and Morro Bay): the red rock crab (Cancer productus), the graceful crab (Cancer gracilis), and the Dungeness crab (Cancer magister). Juvenile 
crabs of all three species were found at Bodega Bay when sampling for this study (personal observation). Because geoducks typically live below mean lower low water, predators such as fishes may also feed on geoducks. Anderson (1971) observed that siphon damage caused by predatory fishes, such as the cabezon (Scorpaenichthys marmoratus) and the spiny dogfish (Squalus acanthias) could impact a growth. Both fishes are known to frequent Bodega Bay and Morro Bay waters and occur commonly at the subtidal locations sampled. One additional voracious predator, the sea otter (Enhydra lutris), is capable of feeding on geoducks, primarily in subtidal locations. There are reports from subtidal sites in southeast Alaska and Monterey Harbor, California confirming that otters prey on deep-burrowing clams and that they are able to excavate them as deep as $0.5 \mathrm{~m}$ in the sediment (Kvitek 1993; Hines and Loughlin 1980). This maximum observed sediment depth is half of a clam's siphon length, which could be providing a burial depth refuge from otters. Morro bay has a resident sea otter population, which could explain the lack of old clams in that location if predation occurs during high tides. However, otters do not occur in Bodega Bay, where clams are also much younger than average.

Recreational fishing may provide an explanation for increased longevity in subtidal sites and truncation in older age classes in intertidal sites. In California, clams are primarily harvested recreationally from intertidal locations by digging for them at low tide. There is currently no harvest allowed for subtidal clams in California. Recreational clamming for geoducks is high in Bodega Bay (personal 
observation) when tides are low enough to dig up clams. From the seven creel surveys conducted by the CDFW (personal communication, Christy Juhasz) between 2012- 2013 catch per unit effort (CPUE) was estimated at 0.005 with a total of 358 recreational clammers that year. The current CPUE maximum is set at three geoducks per person per day in California. Morro Bay, the other intertidal site in this study, was declared a State Marine Recreational Management Area (SMRMA) in 2007, which restricts take of living marine resources (CDFW 2015). Prior to the closure, clamming activities in this area were primarily targeting Pismo clams. The decline of Pismo clams could have shifted fishing pressure to geoducks. However, there is no data available to support this. Geoducks are long-lived, reaching ages over 100 years (Bureau et al. 2002). The Morro Bay SMRMA closure is recent relative to the generation time of $P$ generosa, and thus the effects of past fishing pressure will likely be visible in the age structure for many decades to follow.

How body size changes as a function of age in $P$. generosa may be used for stock assessment of this species. Traditionally, studies have used the von Bertalanffy growth model (VBGM) to understand size-at-age distributions in $P$. generosa (Goodwin and Shaul 1984; Hoffmann et al. 2000; Calderon-Aguilera et al. 2010a). González- Peláez et al. (2015) compared seven growth curve models and found the Gompertz growth model to be a more solid predictive model of size-at-age data in $P$. globosa compared to other growth models based on the Aikaike Information Criterion (AIC) value. However, differences in AIC values 
between the Gompertz growth model and the VBGM were not statistically significant. The difference between these models is related to the sigmoidal curve inflection points and maximum lengths. Employing the Gompertz model in this study could inflate the maximum valve lengths observed and make future comparisons to other studies difficult. To enable comparisons with other studies, the traditional VBGM model was used in this study. The growth coefficient, $\mathrm{K}$, in the VBGM is indicative of how fast a maximum length or $L_{\text {inf }}$ is reached. Growth curve coefficients as part of this study ranged from $K=0.15$ to $K=0.25$. This range falls within reported ranges for $P$. generosa populations in British Columbia, Washington, and Baja California (Hoffmann et al. 2000; Campbell and Ming 2003; Calderon-Aguilera 2010) and showed weak correlations with environmental correlates. The largest geographic difference in the VBGM was observed in the predicted maximum asymptotic length parameter $L_{\text {inf. }}$ Low sample sizes may have precluded the detection of statistically significant correlations between $\mathrm{L}_{\text {inf }}$ and the environmental variables of mean SST and $\mathrm{Chl} a$ (Fig.11). However, $54 \%$ of the variation in $L_{\text {inf }}$ among locations could be explained by average temperature differences and $41 \%$ of the variation could be explained by $\mathrm{Chl}$ a. Asymptotic growth increased with decreasing temperature, greater latitude, and elevated $\mathrm{Chl}$ a levels. These oceanographic factors are closely connected and can influence the structure of marine food webs (Sarmiento et al. 2004). Chl a serves as a proxy for phytoplankton availability, a clam's primary food source, and similar to this study on $P$. generosa, Chl a has 
been shown to positively influence bivalve growth in other systems (Seed and Suchanek 1992). Utting (1988) correlated oyster growth to phytoplankton abundance in the wild, while Smaal and van Stralen (1990) came to the same conclusion when examining growth and conditions of mussels. Pernet et al. (2007) found that temperature was highly correlated to metabolic processes in Mytilus edulis and Crassostrea viriginica.

\section{Spatial Variability in Geoduck Morphology}

Shell shape was described using 15 internal shell landmarks via geometric morphometrics, finding significant geographic variation in morphology. More than half of the spatial variation in shell shape was explained by a dorsoventral compression of the clamshells (Fig. 12). Shell morphology did not change as a function of latitude. Instead, shape variation is likely explained by habitat composition or other environmental variables. Stanley (1970) showed that life modes or habits of clams could indeed influence their morphology or shape. He examined 95 western Atlantic bivalve mollusks representing 29 families, and demonstrated that morphological features of the shell reflect a bivalve's habitat preference. For example, a more streamlined or dorsoventrally compressed shell shape, similar to the shells of $P$. generosa from Catalina Island, characterizes rapid burrowers. Additionally, shell thickness can indicate what type of substrate or disturbance regime a clam resides in. Shell thickness and strength are positively correlated with disturbance frequency (Stanley 1970). 
Geoducks collected at the two intertidal sites and Santa Cruz Island featured very thick shells; all three habitats are high disturbance environments with more exposure to tidal fluctuations than the Catalina Island site. The latter is in a protective harbor often used as shelter for the boating community when storms occur. This protective environment could induce thinner shells in Catalina Island shells inherently allowing them to become more rapid burrowers into the sediment. Recent examination of the biomechanics and burrowing rates in geoducks by Tapia-Morales et al. (2015) indicated that juvenile clams burrowed ten times faster in sand than in mud sediment. Both Morro and Bodega bay featured mud sediment at the clam collection sites, while Catalina and Santa Cruz Islands had fine sand. Shells from Catalina Island were thinner (hence more brittle) and smaller for their age compared to all other sites. Depending on the grain size and burrowing abilities, subsequent growth could be affected such that the clam's morphology adjusts to its environment. Future studies should take sediment cores up to the depth that a clamshell resides in their natural habitat prior to digging them up. Sediment core analyses could lead to quantitative answers as to what properties of the sediment could be driving morphological differences.

Shape was consistent at each site, and did not change with clam age, except at Catalina Island. Thus shape is likely determined more by the habitat and other local conditions present at a site. Hinch et al. (1986) conducted reciprocal transplant experiments with freshwater clams (Lampsilis radiate) 
originating from sand and mud substrates, and found that clams had a phenotypic response to substrate by changing their shell shape, but a genetic response in their growth. However, shape and size can be closely correlated through allometry: as an organism grows into adulthood it can change its shape proportions (Klingenberg 1996). Catalina Island was the only site in this study that featured this very pattern: age estimates predicted residual shape scores (size corrected). Shell shape analyses conducted by Caill-Milly et al. (2012) on the Manila clam Ruditapes philippinarum showed that there was no evidence for genetic intraspecific variation in these clams but rather phenotypic plasticity was driven by local environmental conditions. Similarly, the calm waters in Catalina harbor could be responsible for the difference in its relative shape and shell thinness that could provide geoducks there with more rapid burrowing rates compared to any of the other sites in this study.

\section{Phenotypic Plasticity and the Environment}

With an average larval duration of 47 days, there is a potential for high gene flow and extensive population connectivity across the species range of $P$. generosa, from Alaska to Baja California. Vadopalas et al. (2004) reported genetic patchiness of $P$. generosa populations using microsatellite markers, but their study did not include the entire range of $P$. generosa. Miller et al. (2006) found a significant isolation-by-distance pattern in British Columbia Panopea populations. Strong evidence for geographic variation in life history and 
morphometric traits in $P$. generosa on a larger spatial scale was found in this study. Whether these differences are due to adaptive phenotypic plasticity or non-adaptive phenotypic plasticity in response to variable environmental conditions is unclear, as loci under selection may not be linked to presumed neutral loci such as microsatellites. The response observed here is presumed due to environmental variation via non-adaptive phenotypic plasticity, because of the lack of evidence for genetic population differentiation. Whether or not there is connectivity between California clam populations and sites in Mexico and Washington requires further analyses, and makes for much needed research in this area.

\section{Recommendations for Fishery Management}

This study was a first step toward understanding California geoduck populations in comparison to other Pacific coast locations with abundant clam populations that are currently managed and fished. Considering geoducks' profitability in Washington, Mexico, British Columbia, and Alaska, this study was a necessary first of many steps to address the level of management this clam may require in California waters. More information is needed to make conclusions about the drivers behind population differentiation observed in this study. Further investigation of morphological plasticity and the above mentioned environmental traits affecting geoduck populations could aid managers with decisions on transplanting of juvenile clams across substrate types, should there 
be an interest in developing a geoduck aquaculture fishery in California. Aging samples from California may help elucidate when these populations established at a particular site. If, for instance, different age groups are found in the same area, we can conclude that there were settlement pulses occurring in different years. If all clams in an area show the same age, we can conclude there to be one major settlement pulse in that particular area. The two intertidal populations examined showed a truncation in older age classes compared to subtidal sites. Using aquaculture techniques such as seeding of clams could ameliorate this pattern. Further analysis of growth patterns (e.g. distance between annuli) could lead to an understanding of clam growth at particular sites. Managers could use this information to inform fisheries model and stock assessment for $P$. generosa, which seek to forecast population biomass and target catch levels under different harvesting regimes. Life history and demographic information from this study will provide the critical parameters needed for those population modeling efforts.

Because geoducks exhibit significant spatial variability in life history traits, fisheries managers may use that information to develop regional-specific fisheries regulations and management plans, tuned to the demographic variability present along the coast.

Finally, resource managers would benefit from an improved understanding of population abundance and spatial aggregation patterns in geoducks. SCUBA surveys could help identify patterns of variability in population density throughout the state, and inform decisions of where fishing should be allowed. It is unknown 
whether California populations would be able to sustain a commercial fishery at this point in time, yet density studies as well as sex-ratio distributions could elucidate fishery sustainability, along with information on the life history and demography provided here.

\section{Conclusion}

Geographically distinct locations may differ in environmental conditions from physical oceanographic factors such as sea surface temperatures and chlorophyll a levels, or geologic factors such as sediment composition. In addition, sites may vary spatially in harvest pressure, predation risk, disease, or parasites, which could influence life history and morphological traits. The present study used Pacific geoduck, Panopea generosa, populations from Washington, California, and Mexico to reveal variation in life history traits and morphology over large geographic scales. The high profitability of $P$. generosa in Washington and Mexico could lead to interest in developing a commercial fishery or aquaculture industry for these clams in California. However, more research is needed to make management recommendations. 


\section{Literature Cited}

Adams, D. C., Rohlf, F. J., \& Slice, D. E. (2013). A field comes of age: geometric morphometrics in the 21st century. Hystrix, the Italian Journal of Mammalogy, 24(1), 7-14.

Agrawal, A. A. (2001). Phenotypic plasticity in the interactions and evolution of species. Science, 294(5541), 321-326.

Almeland, O. W. (2015). Phenotypic plasticity in Atlantic herring (Clupea harengus) juveniles reared at two different salinities (Master Thesis). The University of Bergen, Norway.

Andersen, A. M., Jr. (1971). Spawning, growth and spatial distribution of the geoduck clam, Panopea abrupta (Gould) in Hood Canal, Washington (Doctoral Dissertation). University of Washington, Seattle.

Aragón-Noriega, E. A., Alcántara-Razo, E., Calderon-Aguilera, L. E., \& SánchezFourcade, R. (2012). Status of geoduck clam fisheries in Mexico. Journal of Shellfish Research, 31(3), 733-738.

Armstrong, J., Armstrong, D., \& Hilborn, R. (1998). Crustacean resources are vulnerable to serial depletion-the multifaceted decline of crab and shrimp fisheries in the Greater Gulf of Alaska. Reviews in Fish Biology and Fisheries, 8(2), 117-176.

Atkinson, D. (1994). Temperature and organism size- a biological law for ectotherms? Advances in Ecological Research, 25, 1-58.

Bautista-Romero, J. J., González-Peláez, S. S., Morales-Bojórquez, E., HidalgoDe-La-Toba, J. A., \& Lluch-Cota, D. B. (2015). Sinusoidal function modeling applied to age validation of geoducks Panopea generosa and Panopea globosa. Journal of Shellfish Research, 34(1), 21-29.

Begg, G. A., Hare, J. A., \& Sheehan, D. D. (1999). The role of life history parameters as indicators of stock structure. Fisheries Research, 43(1), 141-163.

Bergmann, C. (1847). Über die Verhältniss der Wärmökonomie der Thiere zu ihrer Größe. Göttinger Studien, 3, 595-708.

Bernard, F. R. (1983). Catalogue of the living bivalvia of the eastern Pacific Ocean: Bering Straight to Cape Horn. Canadian Special Publication of Fisheries and Aquatic Sciences, 61,102. 
Black, B. A., Gillespie, D. C., MacLellan, S. E., \& Hand, C. M. (2008). Establishing highly accurate production-age data using the tree-ring technique of crossdating: a case study for Pacific geoduck (Panopea abrupta). Canadian Journal of Fisheries and Aquatic Sciences, 65, 25722578.

Black, B. A. (2009). Climate-driven synchrony across tree, bivalve, and rockfish growth-increment chronologies of the northeast Pacific. Marine EcologyProgress Series, 378, 37-46.

Blanckenhorn, W. U., \& Demont, M. (2004). Bergmann and converse Bergmann latitudinal clines in arthropods: two ends of a continuum? Integrative and Comparative Biology, 44(6), 413-424.

Bookstein, F. L. (1978). The measurement of biological shape and shape change: Lecture notes in Biomathematics (Vol. 24). Berlin, Springer Verlag.

Bookstein, F. L. (1991). Morphometric tools for landmark data: geometry and biology. Cambridge, Cambridge University Press.

Bookstein, F. L. (1996). Biometrics, biomathematics and the morphometric synthesis. Bulletin of Mathematical Biology, 58, 313-365.

Bookstein, F. L. (1997). Landmark methods for forms without landmarks: morphometrics of group differences in outline shape. Medical Image Analysis, 1, 225-243.

Bookstein, F. L. (1998). A hundred years of morphometrics. Acta Zoologica Academiae Scientiarum Hungaricae, 44, 7-59.

Bookstein, F. L., Chernoff, B., Elder, R. L., Humphries, J. M., Smith, G. R., \& Strauss, R. E. (1985). Morphometrics in evolutionary biology: The geometry of size and shape change, with examples from fishes (Vol.15). Philadelphia, Academy of Natural Sciences of Philadelphia.

Bourdeau, P. E. (2011). Constitutive and inducible defensive traits in cooccurring marine snails distributed across a vertical rocky intertidal gradient. Functional Ecology, 25, 177-185.

Breen, P. A., \& Shields, T. L. (1983). Age and size structure in five populations of geoduck clams (Panopea generosa) in British Columbia. Canadian Technical Report of Fisheries and Aquatic Sciences, 1169. 
Bureau, D., Rajas, W., Surry, N. W., Rand, C. M., Dovey, G., \& Campbell, A. (2002). Age, size structure and growth parameters of geoducks (Panopea abrupta, Conrad 1849) from 34 locations in British Columbia sampled between 1993 and 2000. Canadian Technical Report of Fisheries and Aquatic Sciences, 2413.

Caill-Milly, N., Bru, N., Mahé, Borie, C., \& D'Amico, F. (2012). Shell shape analysis and spatial allometry patterns of Manila clam (Ruditapes philippinarum) in a mesotidal coastal lagoon. Journal of Marine Biology, 2012.

Calderon-Aguilera, L. E., Aragón-Noriega, E. A., Hand, C. M., \& Moreno-Rivera, V. M. (2010a). Morphometric relationships, age, growth, and mortality of the geoduck clam, Panopea generosa, along the Pacific coast of Baja California, Mexico. Journal of Shellfish Research, 29(2), 319-326.

Caley, M. J., Carr, M. H., Hixon, M. A., Hughes, T. P., Jones, G. P., \& Menge, B. A. (1996). Recruitment and the Local Dynamics of Open Marine Populations. Annual Review of Ecology and Systematics, 27, 477-500.

California Department of Fish and Wildlife (2015). Morro Bay Marine Protected Areas. Retrieved from $<$ http://californiampas.org/pubs/MPABrochures/Morro_Bay_final.pdf>.

Campbell, A., \& Ming, M. D. (2003). Maturity and growth of the Pacific geoduck clam, Panopea abrupta, in Southern British Columbia, Canada. Journal of Shellfish Research, 22, 85-90.

Caselle, J. E., Hamilton, S. L., Schroeder, D. M., Love, M. S., Standish, J. D., Rosales-Casian, J. A., \& Sosa-Nishizaki, O. (2011). Geographic variation in density, demography, and life history traits of a harvested, sexchanging, temperate reef fish. Canadian Journal of Fisheries and Aquatic Sciences, 68(2), 288-303.

Chan, M. D. (2001). Fish ecomorphology: predicting habitat preferences of stream fishes from their body shape (Doctoral Dissertation). University Rome Tor Vergata, Rome.

Chivers, D. P., Kiesecker, J. M., Marco, A., Devito, J., Anderson, M. T., \& Blaustein, A. R. (2001). Predator-induced life history changes in amphibians: egg predation induces hatching. Oikos, 92(1), 135-142. 
Choat, J. H., \& Robertson, D. R. (2002). Age-based studies on coral reef fishes. In Coral reef fishes: Dynamics and diversity in a complex ecosystem. Academic Press, New York.

Coan, E. V., Scott, P. H., \& Bernard, F. R. (2000). Bivalve seashells of western North America. Santa Barbara Museum of Natural History Publication, Santa Barbara, California.

Connell, J. H. (1961.) The influence of interspecific competition and other factors on the distribution of the barnacle Chthamalus stellatus. Ecology, 42(4), 710-723.

Conover, D. O., \& Munch, S. B. (2002). Sustaining fisheries yields over evolutionary time scales. Science, 297(5578), 94-96.

Conover, D. O., \& Schultz, E. T. (1995). Phenotypic similarity and the evolutionary significance of countergradient variation. Trends in Ecology and Evolution, 10(6), 248-252.

Costa, L. d. F., \& Cesar, R. M., Jr. (2001). Shape analysis and classification: Theory and practice. CRC Press, Boca Raton.

Costa, C., Aguzzi, J., Menesatti, P., Anonucci, F., Rimatori, V., \& Mattoccia, M. (2008). Shape analysis of different populations of clams in relation to their geographical structure. Journal of Zoology, 276, 71-80.

Dayton, P. K. (1971). Competition, disturbance, and community organization: the provision and subsequent utilization of space in a rocky intertidal community. Ecological Monographs, 41, 351-389.

Daufresne, M., Lengfellner, K., \& Sommer, U. (2013). The relative importance of predation risk and water temperature in maintaining Bergmann's rule in a marine ectotherm. American Naturalist, 182(3), 347-358.

DeMartini, E. E., Friedlander, A. M., \& Holzwarth, S. R. (2005). Size at sex change in protogynous labroids, prey body size distributions, and apex predator densities at NW Hawaiian atolls. Marine Ecology Progress Series, 297, 259-271.

Denny, M. W., Daniel, T. L., \& Koehl, M. A. R. (1985). Mechanical limits to size in wave-swept organisms. Ecological Monograph, 55(1), 69-102.

Dryden, I. L., \& Mardia, K. V. (1998). Statistical shape analysis. Chichester, Wiley. 
Enberg, K., Jørgensen, C., Dunlop, E. S., Varpe, Ø., Boukal, D. S., Baulier, L., \& Heino, M. (2012). Fishing-induced evolution of growth: concepts, mechanisms and the empirical evidence. Marine Ecology, 33(1), 1-25.

Etter, R. (1989). Life history variation in the intertidal snail Nucella lapillus across a wave-exposure gradient. Ecology, 70(6), 1857-1876.

Fenberg, P. B., \& Kaustuv, R. (2012). Anthropogenic harvesting pressure and changes in life history: Insights from a rocky intertidal limpet. American Naturalist, 180, 200-210.

Fleming, I. A., \& Gross, M. R. (1990). Latitudinal clines: a trade-off between egg number and size in Pacific salmon. Ecology, 71(1), 1-11.

Frank, P. W. (1975). Latitudinal variation in the life history features of the black turban snail Tegula funebralis (Prosobranchia: Trochidae). Marine Biology, $31,181-192$.

Gleason, L. U., \& Burton, R. S. (2013). Phenotypic evidence for local adaptation to heat stress in the marine snail Chlorostoma (formerly Tegula) funebralis. Journal of Experimental Marine Biology and Ecology, 448, 360366.

Goddard Earth Sciences Data and Information Services Center (GES DISC). (2015). Retrieved from http://disc.sci.gsfc.nasa.gov.

González-Peláez, S. S., Leyva-Valencia, I., \& Lluch-Cota, D. B. (2013). Distribution limits of the geoduck clams Panopea generosa and $P$. globosa on the Pacific coast of Mexico. Malacologia, 56(2), 85-94.

González-Peláez, S. S., Morales-Bojórquez, E., Lluch-Cota, D. B., Lluch-Cota, S. E., \& Bautista-Romero, J. J. (2015). Modeling geoduck growth: multimodel inference in Panopea globosa from the southwestern Baja California Peninsula, Mexico. Journal of Shellfish Research, 34(1), 101-112.

Goodall, C. (1991). Procrustes methods in the statistical analysis of shape. Journal of the Royal Statistical Society. Series B (Methodological), 53(2), 285-339.

Goodwin, C. L., Shaul, W., \& Budd, C. (1979). Larval development of the geoduck clam (Panopea abrupta, Gould). Proceedings of the National Shellfisheries Association, 69, 73-76.

Goodwin, C. L., \& Shaul, W. (1984). Age, recruitment and growth of the geoduck 
clam (Panopea generosa, Gould) in Puget Sound, Washington. Washington Department of Fisheries Progress Report, 215.

Goodwin, C. L., \& Pease, B. C. (1987). The distribution of geoduck (Panopea abrupta) size, density and quality in relation to habitat characteristics such as geographic area, water depth, sediment type and associated flora and fauna in Puget Sound, Washington. Department of Fisheries. Technical Report no.102. Olympia, Washington.

Goodwin, C. L., \& Pease, B. C. (1989). Species profiles: life histories and environmental requirements for coastal fishes and invertebrates (Pacific Northwest)- Pacific geoduck clam, U.S. Fish and Wildlife Service Biological Report, 82(11.120), U.S. Army Corps of Engineers, TR EL82-4. $14 \mathrm{pp}$.

Goodwin, C. L., \& Pease, B. C. (1991). Geoduck, Panopea abrupta (Conrad, 1849) size, density, and quality as related to various environmental parameters in Puget Sound, Washington. Journal of Shellfish Research, 10(1), 65-77.

González-Peláez, S. S., Moralez-Bojórquez, E., Lluch-Cota, D. B., Lluck-Cota, S. E., \& Bautista-Romero, J. J. (2015). Modeling geoduck growth: multimodel inference in Panopea globosa from the southwestern Baja California peninsula, Mexico. Journal of Shellfish Research, 34(1), 101-112.

Gunz P., Mitteroecker P., \& Bookstein F. L. (2005). Semilandmarks in three dimensions. In: Slice D.E. (Ed.). Modern Morphometrics in Physical Anthropology. Kluwer Academic/Plenum Publishers, New York, 73-98.

Gunz, P., \& Mitteroecker, P. (2013). Semilandmarks: a method for quantifying curves and surfaces. Hystrix, the Italian Journal of Mammology, 24(1), 103-109.

Hagen, D. W., \& Gilbertson, L. G. (1972). Geographic variation and environmental selection in Gasterosteus aculeatus in the Pacific Northwest, America. Evolution, 26, 32-51.

Hagen, D. W., \& Gilbertson, L. G. (1973). Selective predation and the intensity of selection acting upon the lateral plates of threespine sticklebacks. Heredity, 30, 273-287. 
Hamilton, S. L., Caselle J. E., Standish J. D., Schroeder D. M., Love M. S., Rosales-Casian, J. A., \& Sosa-Nishizaki, O. (2007). Size-selective harvesting alters life histories of a temperate sex-changing fish. Ecological Applications, 17, 2268-2280.

Hamilton, S. L., Wilson, J. R., Ben-Horin, T., \& Caselle, J. E. (2011). Utilizing spatial demographic and life history variation to optimize sustainable yield of a temperate sex-changing fish. PloS one, 6(9), e24580-e24580.

Harvey, H. W. (1942). Production of life in the sea. Biological Reviews, 17(3), 221-246.

Heilmayer, O., Brey, T., \& Pörtner, H. O. (2004). Growth efficiency and temperature in scallops: a comparative analysis of species adapted to different temperatures. Functional Ecology, 18(5), 641-647.

Hennessy, R. J., Kinsella, A., \& Waddington, J. L. (2002). 3D laser surface scanning and geometric morphometric analysis of craniofacial shape as an index of cerebro-craniofacial morphogenesis: initial application to sexual dimorphism. Biological Psychiatry, 51, 507-514.

Hennessy, R. J., \& Moss, J. P. (2001). Facial growth: separating shape from size. European Journal of Orthodontics, 23, 275-285.

Hidalgo-De-La-Toba, J. A., González-Peláez, S. S., Morales-Bojórquez, E., Bautista-Romero, J. J., \& Lluch-Cota, D. B. (2015). Geoduck, Panopea generosa, growth at its southern distribution limit in North America using a multimodel inference approach. Journal of Shellfish Research, 34(1), 9199.

Hinch, S. G., Bailey, R. C., \& Green, R. H. (1986). Growth of Lampsilis radiata (Bivalvia: Unionidae) in sand and mud: a reciprocal transplant experiment. Canadian Journal of Fisheries and Aquatic Sciences, 43(3), 548-552.

Hines, A. H., \& Loughlin, T. R. (1980). Observations of sea otters digging for clams at Monterey Harbor, California. Fisheries Bulletin, 78, 159-163.

Hoffman, G. L. (1956). The life cycle of Crassiphiala bulboglossa (Trematoda: Strigeida). Development of the metacercaria and cyst, and effect on the fish host. The Journal of Parasitology, 42(4), 435-444.

Hoffmann, A., Bradbury, A., \& Goodwin, C. L. (2000). Modeling geoduck, Panopea abrupta (Conrad, 1849) population dynamics. I. Growth. Journal of Shellfish Research, 19(1), 57-62. 
Hutchings, J. A. (2005). Life history consequences of overexploitation to population recovery in Northwest Atlantic cod (Gadus morhua). Canadian Journal of Fisheries and Aquatic Sciences, 62(4), 824-832.

Innes, D. J., \& Bates, A. (1999). Morphological variation of Mytilus edulis and Mytilus trossulus in eastern Newfoundland. Marine Biology, 133, 691-699.

Jamison, D., Heggen, R., \& Lukes, J. (1984). Underwater video in a regional benthos survey. In Proceedings of the Pacific Congress on Marine Technology. Marine Technology Society, Honolulu, Hawaii.

Jensen, G. C. (1995). Pacific coast crabs and shrimps. Sea Challengers, Monterey.

Jivoff, P. (2003). A review of male mating success in the blue crab, Callinectes sapidus, in reference to the potential for fisheries-induced sperm limitation. Bulletin of Marine Science, 72(2), 273-286.

Jørgensen, T. (1990). Long-term changes in age at sexual maturity of Northeast Arctic cod (Gadus morhua). Journal du Conseil: ICES Journal of Marine Science 46(3), 235-248.

Kendall, D. G. (1977). The diffusion of shape. Advances in Applied Probability, 9(3), 428-430.

Kendall, D. G., Barden, D., Carne, T. K., \& Le, H. (1999). Shape and shape theory. Chichester, Wiley.

Kinlan, B. P., Gaines, S. D., \& Lester, S.E. (2005). Propagule dispersal and the scales of marine community process. Diversity and Distributions, 11(2), 139-148.

Klingenberg, C. P., Barluenga, M., \& Meyer, A. (2003). Body shape variation in cichlid fishes of the Amphilophus citrinellus species complex. Biological Journal of the Linnean Society, 80(3), 397-408.

Klingenberg, C. P. (2011). MorphoJ: An integrated software package for geometric morphometrics. Molecular Ecology Resources, 11(2), 353-357.

Koehn, R. K., Milkman, R., \& Mitton, J. B. (1976). Population genetics of marine Pelecypods. Evolution, 30(1), 2-32.

Kvitek, R. G, Bowlby, C. E., \& Staedler, M. (1993). Diet and foraging behavior of sea otters in southeast Alaska. Marine Mammal Science, 9(2), 168-181. 
Law, R. (2000). Fishing, selection, and phenotypic evolution. ICES Journal of Marine Science: Journal du Conseil, 57(3), 659-668.

Law, R. (2007). Fisheries-induced evolution: present status and future directions. Marine Ecology Progress Series, 335, 271-277.

Lele, S. R., \& Richtsmeier, J. T. (2001). An invariant approach to statistical analysis of shapes. Boca Raton, Chapman \& Hall/CRC.

Levins, R. (1968). Evolution in changing environments. Princeton University Press, Princeton, New Jersey.

Levins, R. (1969). Thermal acclimation and heat resistance in Drosophila species. American Naturalist, 103, 483-499.

Leyva-Valencia, I., Ticul Álvarez-Castañeda, S., Lluch-Cota, D. B., GonzálezPeláez, S., Pérez-Valencia, S., Vadopalas, B., Ramírez-Pérez, S., \& CruzHernández, P. (2012). Shell shape differences between two Panopea species and phenotypic variation among $P$. globosa at different sites using two geometric morphometrics approaches. Malacologia, 55(1), 1-13.

Libungan, L. A., Óskarsson, G. J., Slotte, A., Jacobsen, J. A., \& Pálsson, S. (2015). Otolith shape: A population marker for Atlantic herring Clupea harengus. Journal of Fish Biology, 86(4), 1377-1395.

Lindsey, C. C. (1966). Body sizes of poikilotherm vertebrates at different latitudes. Evolution, 20(4), 456-465.

Longhurst, A. R. (2010). Ecological geography of the sea. Academic Press.

Lonsdale, D. J., \& Levinton, J. S. (1985). Latitudinal differentiation in copepod growth: an adaptation to temperature. Ecology, 66(5), 1397-1407.

Loher, T., \& Armstrong, D. A. (2005). Historical changes in the abundance and distribution of ovigerous red king crabs (Paralithodes camtschaticus) in Bristol Bay (Alaska), and potential relationship with bottom temperature. Fisheries Oceanography, 14(4), 292-306.

MacDonald, B. A., \& Thompson, R. J. (1985). Influence of temperature and food availability on the ecological energetics of the giant scallop Placopecten magellanicus. I. Growth rates of shell and somatic tissue. Marine Ecology Progress Series, 25, 279-294. 
Marcus, L. F., Corti, M., Loy, A., Naylor, G. J. P., \& Slice, D. E. (1996). Advances in Morphometrics. New York, NY.

Mauzey, K. P., Birkeland, C., \& Dayton, P. K. (1968). Feeding behavior of asteroids and escape responses of their prey in the Puget Sound region. Ecology, 49, 603-619.

Miller, L. P., \& Denny, M. W. (2011). Importance of behavior and morphological traits for controlling body temperature in littorinid snails. The Biological Bulletin, 220(3), 209-223.

Miller, K. M., Supernault, K. J., Li, S., \& Withler, R. (2006). Population structure in two marine invertebrate species (Panopea abrupta and Strongylocentrotus franciscanus) targeted for aquaculture and enhancement in British Columbia. Journal of Shellfish Research, 25(1), 33-42.

Miura, O., Kuris, A. M., Torchin, M. E., Hechinger, R. F., \& Chiba, S. (2006). Parasites alter host phenotype and may create a new ecological niche for snail hosts. Proceedings of the Royal Society of London B: Biological Sciences, 273(1592), 1323-1328.

Ogle, D.H. (2015). FSA: Fisheries Stock Analysis [R package version 0.6.16]. Available from http://www.rforge.net/FSA/InstallFSA.R.

Page, H. M., \& Hubbard, D. M. (1987). Temporal and spatial patterns of growth in mussels Mytilus edulis on an offshore platform: relationships to water temperature and food availability. Journal of Experimental Marine Biology and Ecology, 111(2), 159-179.

Palmer, M., Pons, G. X., \& Linde, M. (2004). Discriminating between geographical group of a Mediterranean commercial clam [Chamelea gallina (L.): Veneridae] by shape analysis. Fisheries Research, 67, 93-98.

Parsons, K. (1997). Contrasting patterns of heritable geographic variation in shell morphology and growth potential in the marine gastropod Bembicium vittatum: Evidence from field experiments. Evolution, 51(3). 784-796.

Pérez-Valencia, S. A., \& Aragón-Noriega, E. A. (2013). Age and growth of the Cortes geoduck Panopea globosa in the upper Gulf of California. Indian Journal of Geo-Marine Sciences, 42(2), 201-205.

Pernet, F., Tremblay, R., Comeau, L., \& Guderley, H. (2007). Temperature adaptation in two bivalve species from different thermal habitats: 
energetics and remodeling of membrane lipids. Journal of Experimental Biology, 210, 2999-3014.

Phillips, P. C., Whitlock, M. C., \& Fowler, K. (2001). Inbreeding changes the shape of the genetic covariance matrix in Drosophila melanogaster. Genetics, 158, 1137-1145.

Pimentel, R. A. (1978). Morphometrics: the multivariate analysis of biological data. Dubuque, lowa. Kendall Hunt/Hunt.

Pineda, J., Porri, F., Starczak, V., \& Blythe, J. (2010). Causes of decoupling between larval supply and settlement and consequences for understanding recruitment and population connectivity. Journal of Experimental Marine Biology and Ecology, 392, 9-21.

Pulcini, D., Costa, C., Aguzzi, J., \& Cataudella, S. (2008). Light and shape: a contribution to demonstrate morphological differences in diurnal and nocturnal teleosts. Journal of Morphology, 269(3), 375-385.

Ray, C. (1960). The application of Bergmann's and Allen's rules in poikilotherms. Journal of Morphology, 106(1), 85-108.

Relyea, R. A. (2001). Morphological and behavioral plasticity of larval anurans in response to different predators. Ecology, 82(2), 523-540.

Relyea, R. A. (2002). Costs of phenotypic plasticity. The American Naturalist, 159(3), 272-282.

Relyea, R. A., \& Auld, J. R. (2005). Predator- and competitor-induced plasticity: how changes in foraging morphology affect phenotypic trade-offs. Ecology, 86(7), 1723-1729.

Reyment, R. A., Blackith, R. E., \& Campbell, N. A. (1984). Multivariate morphometrics. London, Academic Press.

Ricker, W. E. (1975). Computation and interpretation of biological statistics of fish populations. Bulletin of the Fisheries Research Board of Canada, 191, 1382.

Ricketts, E. F., Calvin, J., \& Hedgpeth, J. W. (1968). Between Pacific Tides. $4^{\text {th }}$ ed. Stanford University Press, Stanford, California. 
Robertson, D. R., Ackerman, J. L., Choat, J. H., Posada, J. M., \& Pitt, J. (2005). Ocean surgeonfish Acanthurus bahianus. I. The geography of demography. Marine Ecology Progress Series, 295, 229-244.

Rocha-Olivares, A., Calderon-Aguilera, L. E., Aragon-Noriega, E. A., SaavedraSotelo, N. C., \& Moreno-Rivera, V.M. (2010). Genetic and morphological variation of northeast Pacific Panopea clams: evolutionary implications. Journal of Shellfish Research, 29(2), 327-335.

Rohlf, F. J., \& Slice, D. (1990). Extension of the procrustes method for the optimal superimposition of landmarks. Systematic Biology, 39, 40-59.

Rohlf, F. J., \& Marcus, L.F. (1993). A revolution in morphometrics. Trends in Ecology and Evolution, 8, 129-132.

Ruttenberg, B. I., Haupt, A. J., Chiriboga, A. I., \& Warner, R. R. (2005). Patterns, causes and consequences of regional variation in the ecology and life history of a reef fish. Oecologia, 195, 394-403.

Sanford, E., \& Kelly, M. W. (2011). Local adaptation in marine invertebrates. Annual Review of Marine Science, 3, 509-535.

Sarmiento, J. L., Gruber, N., Brzesinski, M. A., \& Dunne, J. P. (2004). Highlatitude controls of thermocline nutrients and low latitude biological productivity. Nature, 427, 56-60.

Schneider, C. A., Rasband, W. S., \& Eliceiri, K. W. (2012). NIH Image to ImageJ: 25 years of image analysis. Nature Methods, 9, 671-675.

Seed, R., \& Suchanek T. H. (1992). Population and community ecology of Mytilus. In: The Mussel Mytilus: Ecology, Physiology, Genetics and Culture (ed. E.M. Gosling). Elsevier Science Publishers, Amsterdam.

Shaul, W., \& Goodwin, C. L. (1982). Geoduck (Panope generosa: Bivalvia) age as determined by internal growth lines in the shell. Canadian Journal of Fisheries and Aquatic Sciences, 39(4), 632-636.

Sloan, N. A., \& Robinson, S. M. C. (1983). Winter feeding by asteroids on a subtidal sandbed in British Columbia. Ophelia, 22, 125-140.

Sloan, N. A., \& Robinson, S. M. C. (1984). Age and gonad development in the geoduck clam Panopea abrupta (Conrad) from southern British Columbia, Canada. Journal of Shellfish Research, 4, 131-137. 
Smaal, A. C., \& van Stralen, M. R. (1990). Average annual growth and condition of mussels as a function of food source. Hydrobiologia, 195, 179-188.

Small, C. G. (1996). The statistical theory of shape. New York, Springer Verlag.

Suàrez Moo, P. (2012). Variabilidad genètica del gènero Panopea en el Pacifico nororiental: implicaciones ecològicas y evolutivas (Master Thesis). Centro de Investigación Científica y Educación Superior de Ensenada. Baja California, Mexico.

Stanley, S. (1970). Relation of shell form to life habits of the Bivalvia (Mollusca) (Vol.125). The Geological Society of America, Inc.

Straile, D., \& Hälbich, A. (2000). Life history and multiple antipredator defenses of an invertebrate pelagic predator, Bythotrephes longimanus. Ecology, 81(1), 150-163.

Straus, K. M., Crosson, L. M., \& Vadopalas, B. (2008). Effects of geoduck aquaculture on the environment: a synthesis of current knowledge. Washington Sea Grant Program, University of Washington.

Tapia-Morales, S., García-Esquivel, Z., Vadopalas, B., \& Davis, J. P. (2015). Growth and burrowing rates of juvenile geoducks Panopea generosa and Panopea globosa under laboratory conditions. Journal of Shellfish Research, 34(1), 63-70.

Thorson, J. T. (2015). Spatio-temporal variation in fish condition is not consistently explained by density, temperature, or season for California Current groundfishes. Marine Ecology Progress Series, 526, 101-112.

Tollrian, R. (1995). Predator-Induced morphological defenses: costs, life history shifts, and maternal effects in Daphnia pulex. Ecology, 76(6), 1691-1705.

Trussell, G. C. (2000). Phenotypic clines, plasticity, and morphological trade-offs in an intertidal snail. Evolution, 54(1), 151-166.

Utting, S. D. (1988). The growth and survival of hatchery-reared Ostrea edulis L. spat in relation to environmental conditions at the on-growing site. Aquaculture, 69, 27-38.

Vadopalas, B., Leclair, L. L., \& Bentzen, P. (2004). Microsatellite and allozyme analyses reveal few genetic differences among spatially distinct aggregations of geoduck clams (Panopea abrupta, Conrad 1849). Journal of Shellfish Research, 23, 693-706. 
Vadopalas, B., Armstrong, D., Friedman, C. S., Feldman, K., Van Blaricom, G., Cheney, D., Davis, J. P., Elston, R., \& Suhrbier, A. (2005). Identification of research priorities relevant to geoduck (Panopea abrupta). Aquaculture Environmental Impacts. Prepared for the Washington State Department of Natural Resources.

Vadopalas, B., Leclair, L. L., \& Bentzen, P. (2012). Temporal similarity among year-classes of the Pacific geoduck clam (Panopea generosa Gould 1850): a species exhibiting spatial genetic patchiness. Journal of Shellfish Research, 31(3), 697-709.

Vadopalas, B., Pietsch, T. W., \& Friedman, C. S. (2010). The proper name for the geoduck: resurrection of Panopea generosa (Gould 1850), from the synonymy of Panopea abrupta (Conrad, 1849), (Bivalvia: Myoida: Hiatellidae). Malacologia, 52, 169-173.

Vadopalas, B., Weidman C., \& Cronin, E. K. (2011). Validation of age estimation in geoduck clams using the bomb radiocarbon signal. Journal of Shellfish Research, 30(2), 303-307.

Vadopalas, B., Davis, J. P., \& Friedman, C. S. (2015). Maturation, spawning, and fecundity of the farmed Pacific geoduck Panopea generosa in Puget Sound, Washington. Journal of Shellfish Research, 34(1), 31-37.

Walsh, S. M., Hamilton, S. L., Ruttenberg, B. I., Donovan, M. K., \& Sandin, S. A. (2012). Fishing top predators indirectly affects condition and reproduction in a reef-fish community. Journal of Fish Biology, 80(3), 519-537.

Washington Department of Fish and Wildlife (2015). Wild Stock Commercial Geoduck Fishery. Retrieved from http://wdfw.wa.gov/fishing/shellfish/geoduck/

Watt, C., Mitchell, S., \& Salewski, V. (2010). Bergmann's rule a concept cluster? Oikos, 119, 89-100.

Welch, C. (2012). China's demand for geoducks sends prices, profits soaring in NW. Retrieved from http://www.seattletimes.com/seattle-news/chinasdemand-for-geoducks-sends-prices-profits-soaring-in-nw/

Zelditch, M. L., Swiderski, D. L., \& Sheets, H.D. (2012). Geometric morphometrics for biologists: A primer. Amsterdam, Elsevier. 